\title{
Mechanistic Studies of the Palladium-Catalyzed Desulfinative Cross- Coupling of Aryl Bromides and (Hetero)Aryl Sulfinate Salts
}

\author{
Antoine de Gombert, Alasdair I. McKay, Christopher J. Davis, Katherine M. Wheelhouse,
} and Michael C. Willis*

Cite This: J. Am. Chem. Soc. 2020, 142, 3564-3576

Read Online

ABSTRACT: Pyridine and related heterocyclic sulfinates have recently emerged as effective nucleophilic coupling partners in palladium-catalyzed cross-coupling reactions with (hetero)aryl halides. These sulfinate reagents are straightforward to prepare, stable to storage and coupling reaction conditions, and deliver efficient reactions, thus offering many advantages, compared to the corresponding boron-derived reagents. Despite the success of these reactions, there are only scant details of the reaction mechanism. In this study, we use structural and kinetic analysis to investigate the

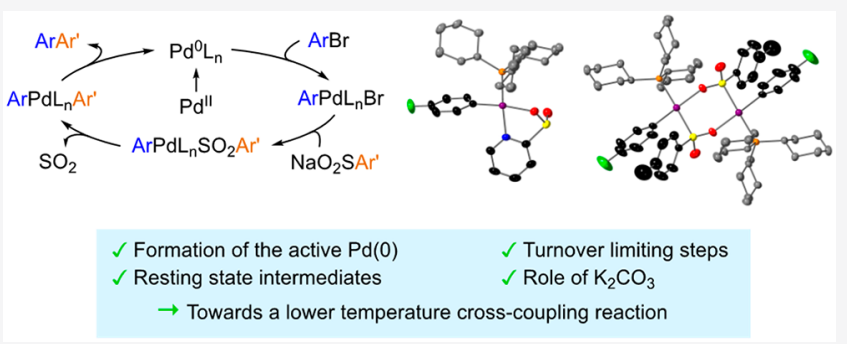
mechanism of these important coupling reactions in detail. We compare a pyridine-2-sulfinate with a carbocyclic sulfinate and establish different catalyst resting states, and turnover limiting steps, for the two classes of reagent. For the carbocyclic sulfinate, the aryl bromide oxidative addition complex is the resting state intermediate, and transmetalation is turnover-limiting. In contrast, for the pyridine sulfinate, a chelated Pd(II) sulfinate complex formed post-transmetalation is the resting-state intermediate, and loss of $\mathrm{SO}_{2}$ from this complex is turnover-limiting. We also investigated the role of the basic additive potassium carbonate, the use of which is crucial for efficient reactions, and deduced a dual function in which carbonate is responsible for the removal of free sulfur dioxide from the reaction medium, and the potassium cation plays a role in accelerating transmetalation. In addition, we show that sulfinate homocoupling is responsible for converting $\mathrm{Pd}(\mathrm{OAc})_{2}$ to a catalytically active $\operatorname{Pd}(0)$ complex. Together, these studies shed light on the challenges that must be overcome to deliver improved, lower temperature versions of these synthetically important processes.

\section{INTRODUCTION}

The Suzuki-Miyaura reaction, ${ }^{1}$ in which a boron-based coupling partner is combined with an aryl halide using a palladium catalyst, has revolutionized synthetic chemistry in the pharmaceutical industry. ${ }^{2}$ However, applying these reactions to the preparation of heteroaromatic derivatives has long remained a challenge, because the corresponding heterocycle-derived boronic acids (and related boron-based reagents) can be challenging to prepare, unstable, basesensitive, and prone to protodeboronation and decomposition under cross-coupling conditions. This is particularly true for pyridine and related diazene-derived boronic acids. ${ }^{3}$ In this context, the Willis laboratory has recently reported the use of pyridyl ${ }^{4}$ and heteroaryl ${ }^{5}$ sulfinate salts as nucleophilic reagents in palladium-catalyzed cross-coupling reactions with aryl and heteroaryl halides (Scheme 1a). These sulfinate salts, several of which are now commercial products, are stable reagents and deliver efficient reactions with challenging coupling partners, thus addressing many of the limitations of their boron counterparts. More recently, the use of related heteroaryl allylsulfones, which function as latent sulfinate coupling partners, has also been reported. ${ }^{6}$
More generally, transition-metal-catalyzed desulfinative cross-coupling has emerged as an effective method for $\mathrm{C}-\mathrm{C}$ bond formation. ${ }^{7}$ First employed for homocoupling with stoichiometric palladium(II), ${ }^{8}$ sulfinate salts can now be employed as the electrophilic coupling partner in MizorokiHeck, ${ }^{9}$ Suzuki-Miyaura, ${ }^{10}$ and Hiyama ${ }^{11}$ cross-coupling processes. Their use as nucleophilic coupling partners was first reported in a 1992 patent, ${ }^{12}$ before being more widely developed for both aromatic ${ }^{13}$ or five-membered $O$ - and $S$ heteroaromatic ${ }^{14}$ systems. Catalytic versions of homocoupling reactions have also been reported. ${ }^{15}$ Together with decarboxylation-based methods, desulfination can be considered as a potentially more sustainable approach to cross-coupling chemistry, relative to processes that require the preparation and use of costly and sensitive organometallic reagents. The release of $\mathrm{SO}_{2}$ gas as the main byproduct should also be considered in this context. While decarboxylation has been

Received: December 9, 2019

Published: February 7, 2020 
Scheme 1. Heterocyclic Sulfinate Coupling Reactions, a Generalized Mechanism, and Aims of the Study

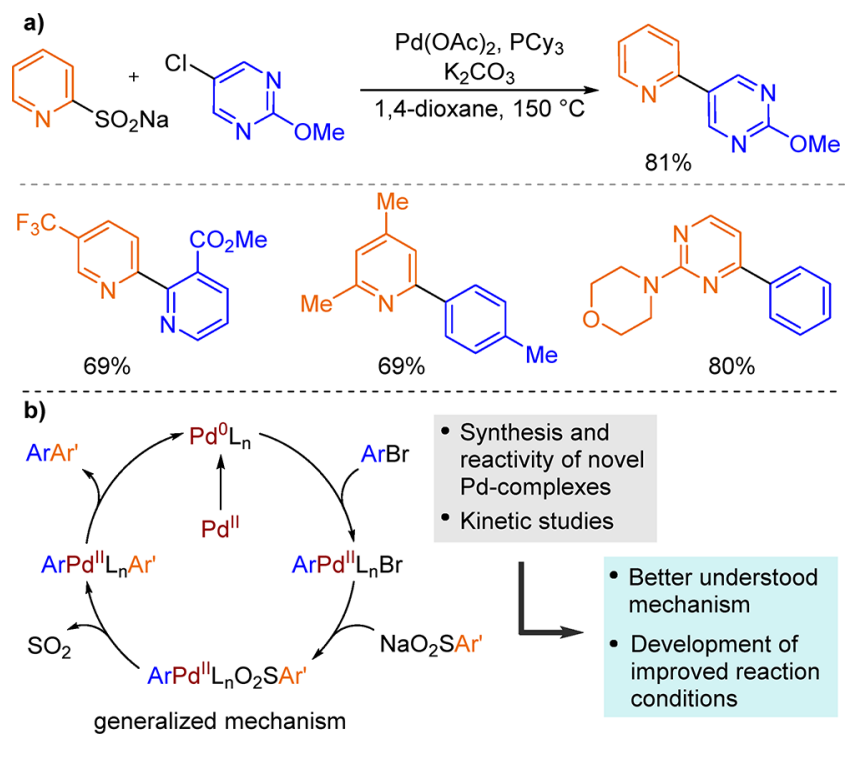

studied both experimentally ${ }^{16}$ and theoretically, ${ }^{17}$ the intrinsic difference between an $\mathrm{sp}^{2}$-hybridized carbon center and an $\mathrm{sp}^{3}$ hybridized sulfur center precludes direct transposition of these studies to the desulfinative variants. Similarly, although carbonylation and sulfur dioxide insertion are related processes, they can follow different mechanistic pathways. ${ }^{18}$ To date, no mechanistic investigation of a desulfinative crosscoupling process using sulfinate salts as nucleophilic coupling partners has been reported. ${ }^{19}$

A generalized mechanism for desulfinative cross-coupling is shown in Scheme 1b. Reduction of the Pd(II) precatalyst to the active $\operatorname{Pd}(0)$ species is followed by oxidative addition of the carbon-bromide bond to the transition metal. Transmetalation between the alkali metal sulfinate salt and the oxidative addition complex generates a putative palladium sulfinate intermediate. Extrusion of $\mathrm{SO}_{2}$ followed by reductive elimination regenerates the $\operatorname{Pd}(0)$ catalyst and delivers product. In the present study, we explore this mechanism using two model sulfinate reagents, allowing the comparison of carbocyclic and heterocyclic substrates. We describe the first synthesis, characterization, and reactivity study of the putative palladium sulfinate intermediates. Using a combination of stoichiometric experiments and kinetic studies, we propose different resting-state intermediates and turnover limiting steps for the two different classes of sulfinate reagent. We also investigate the role of the base, which is a crucial additive for reactivity. The aim of these studies was to improve the understanding of these synthetically important transformations, and also to provide insights for the development of reactions which proceed using milder conditions, particularly with regard to the high temperatures $\left(120-185^{\circ} \mathrm{C}\right)$ generally used in these reactions.?

\section{RESULTS AND DISCUSSION}

2.1. Model Reactions. The coupling of the unsubstituted sodium pyridine-2-sulfinate salt $\mathbf{1}$ with 1-bromo-4-fluorobenzene 2 proceeds in 95\% yield as shown in Scheme 2. Although these reactions were initially developed for pyridine sulfinate salts, ${ }^{4}$ before being extended to a larger class of heteroaromatic substrates, ${ }^{5}$ they can also be applied to carbocyclic variants.
Scheme 2. Substrates and Reactions To Be Studied

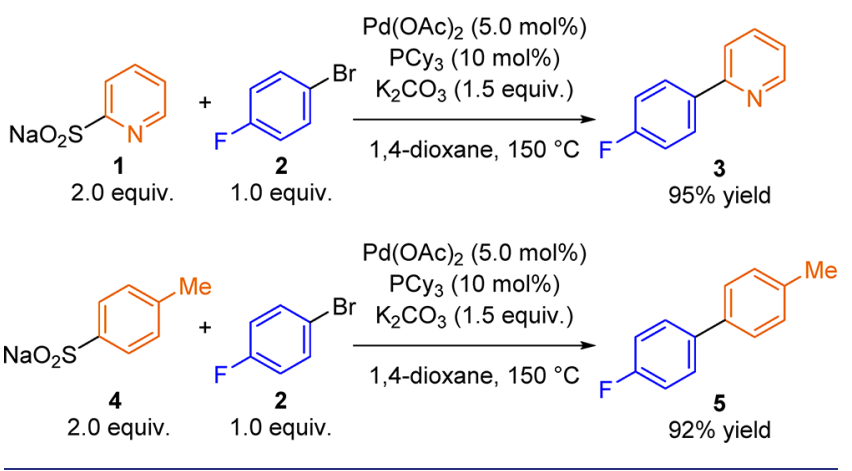

For example, sodium 4-methylbenzenesulfinate 4 can be combined with 1-bromo-4-fluorobenzene using $\mathrm{Pd}(\mathrm{OAc})_{2}$, $\mathrm{PCy}_{3}$, and $\mathrm{K}_{2} \mathrm{CO}_{3}$ at $150{ }^{\circ} \mathrm{C}$ to deliver the cross-coupling product 5 in $92 \%$ yield. Encouraged by the robustness of these reaction conditions, we chose to compare the reactivity of heterocyclic and carbocyclic sulfinate salts, as the carbocyclic variants of this cross-coupling also require high temperatures. ${ }^{7}$ Indeed, such carbocyclic sulfinate salts are inexpensive, benchstable reagents that can be easily prepared via a broad range of methods. ${ }^{20}$ A lower temperature cross-coupling of such reagents would potentially establish sulfinates as attractive alternatives to the more-expensive boron-based reagents. Heterocyclic sulfinate 1 and carbocyclic sulfinate 4, together with aryl bromide $\mathbf{2}$, were therefore selected as the substrates for our proposed mechanistic study.

2.2. Synthesis and Characterization of Organometallic Intermediates. 2.2.1. Formation of the Active Palladium(0) Species. Palladium(II) acetate is employed as the palladium source for these desulfinative cross-coupling reactions, and therefore the active $\operatorname{Pd}(0)$ species must be generated via a reductive process. This step is often overlooked in mechanistic studies, although the $\operatorname{Pd}(0)$ species could be generated from several different pathways and, thus, give rise to different kinetic profiles, ${ }^{21}$ making the understanding of how $\operatorname{Pd}(0)$ is formed crucial for the design of accurate kinetic experiments (section 2.4). Phosphine oxidation has long been known as a pathway for palladium zero generation, ${ }^{22}$ but nucleophilic coupling partners such as organolithium reagents, ${ }^{23}$ organostannanes, ${ }^{24}$ alcohols, ${ }^{25}$ and amines ${ }^{26}$ can also mediate the reduction of $\mathrm{Pd}(\mathrm{II})$ precatalysts. Having observed such reduction pathways, Buchwald and co-workers judiciously used substoichiometric amounts of an aryl boronic acid in order to ensure complete reduction of their $\mathrm{Pd}(\mathrm{II})$ precatalysts. ${ }^{27}$ Furthermore, a synthetically useful dimerization of two sulfinate salts using stoichiometric amounts of $\mathrm{Pd}(\mathrm{II})$ was reported in the early 1970 s. $^{8}$ Therefore, we examined the generation of the active catalyst in the presence of 4methylbenzenesulfinate 4 (Figure 1). The two coupling partners 1-bromo-4-fluorobenzene 2 and 4-methylbenzenesulfinate 4 were introduced to a Young's NMR tube, together with $\mathrm{K}_{2} \mathrm{CO}_{3}$ and stoichiometric amounts of $\mathrm{Pd}(\mathrm{OAc})_{2}$ and $\mathrm{PCy}_{3}$ in a 2:1 ratio. The NMR tube was then gradually heated at different temperatures and the reaction was monitored by ${ }^{31} \mathrm{P}\left\{{ }^{1} \mathrm{H}\right\}$ and ${ }^{19} \mathrm{~F}\left\{{ }^{1} \mathrm{H}\right\}$ NMR spectroscopy. The known $\mathrm{Pd}\left(\mathrm{PCy}_{3}\right)_{2}(\mathrm{OAc})_{2}$ complex $^{28} 6$ was rapidly formed at room temperature. Upon heating to $60{ }^{\circ} \mathrm{C}$, the ${ }^{31} \mathrm{P}\left\{{ }^{1} \mathrm{H}\right\}$ resonance of 6 started to decay to a broad signal at $29.83 \mathrm{ppm}$, corresponding to a set of broad doublets at 8.43 and 6.63 


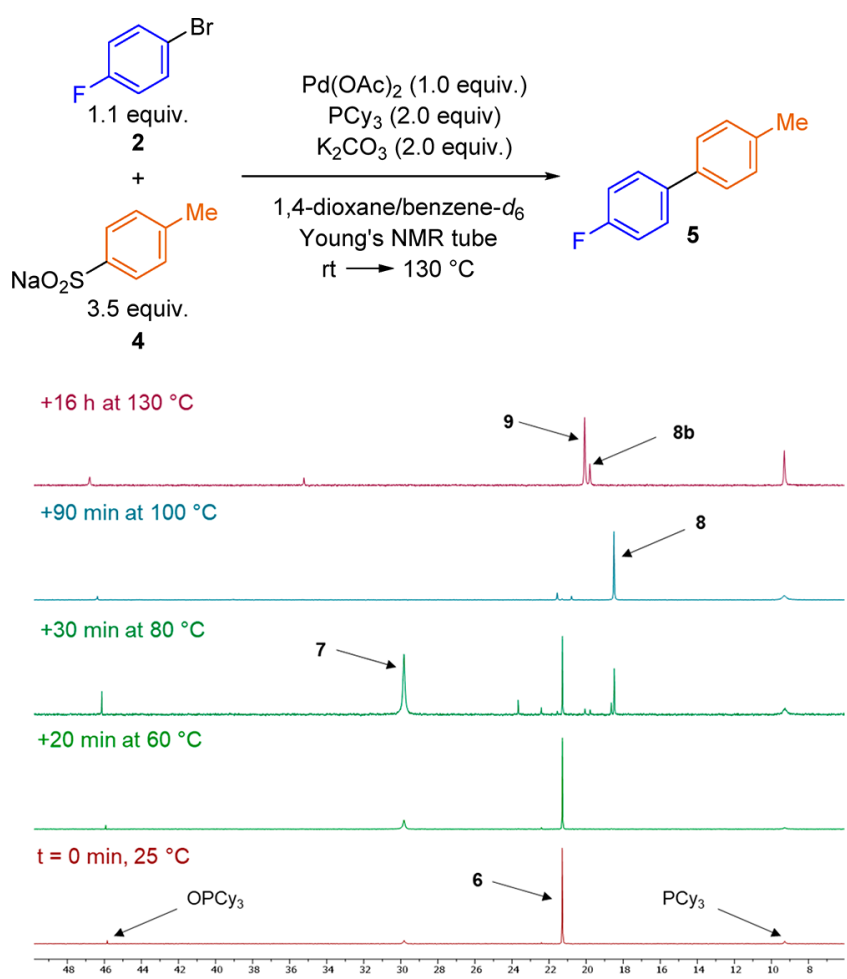

Figure 1. ${ }^{31} \mathrm{P}\left\{{ }^{1} \mathrm{H}\right\}$ NMR spectra of the reaction between $\mathrm{Ar}-\mathrm{Br}(2)$ and $\mathrm{Ar}^{\prime} \mathrm{SO}_{2} \mathrm{Na}(4)$ catalyzed by stoichiometric $\mathrm{Pd}(\mathrm{OAc})_{2}$ and $\mathrm{PCy}_{3}$ in a Young's NMR tube at various temperatures. [Legend: 6, $\mathrm{Pd}(\mathrm{OAc})_{2}\left(\mathrm{PCy}_{3}\right)_{2} ; \quad 7,\left(\mathrm{Ar}^{\prime} \mathrm{SO}_{2}\right) \mathrm{Pd}\left(\mathrm{PCy}_{3}\right)_{2}(\mathrm{OAc}) ; 8, \quad\left(\mathrm{Ar}^{\prime}\right) \mathrm{Pd}-$ $\left(\mathrm{PCy}_{3}\right)_{2}(\mathrm{OAc}) ; \mathbf{8 b}, \quad\left(\mathrm{Ar}^{\prime}\right) \mathrm{Pd}\left(\mathrm{PCy}_{3}\right)_{2}(\mathrm{Br}) ;$ and 9, $(\mathrm{Ar})(\mathrm{Pd})$ $\left(\mathrm{PCy}_{3}\right)_{2}(\mathrm{Br}) ; \mathrm{Ar}=4-\mathrm{F}-\mathrm{C}_{6} \mathrm{H}_{4} ; \mathrm{Ar}^{\prime}=4-\mathrm{Me}-\mathrm{C}_{6} \mathrm{H}_{4}$.]

ppm in the ${ }^{1} \mathrm{H}$ NMR spectrum (see the Supporting Information (SI)).

The complex corresponding to these signals was isolated from a separate reaction that was performed for $16 \mathrm{~h}$ at $60{ }^{\circ} \mathrm{C}$. Single crystals suitable for an X-ray diffraction (XRD) study were grown from $\mathrm{CH}_{2} \mathrm{Cl}_{2}$ /hexane and revealed a sulfinato- $S$ palladium complex 7 (Figures $2 \mathrm{a}$ and $2 \mathrm{~b}$ ). The structure displays a square planar geometry around the $\mathrm{Pd}$ center, with a trans arrangement of the phosphines. The $\mathrm{Pd}-\mathrm{S}$ bond length of 2.2755(4) $\AA$ in 7 is shorter than those in (dppf)Pd$\left(\mathrm{SO}_{2} \mathrm{Me}\right) \mathrm{Cl}^{29}$ and (BINAP) $\mathrm{Pd}\left(\mathrm{SO}_{2} \mathrm{C}_{6} \mathrm{H}_{4} \mathrm{Me}\right) \mathrm{Cl}^{30}$ (2.3262(9) and 2.3331 (7) $\AA$, respectively). While the $\mathrm{Pd}-\mathrm{O}$ bond length of $2.0975(13) \AA$ is notably longer than that in $\left(\mathrm{PCy}_{3}\right)_{2} \mathrm{Pd}$ $(\mathrm{OAc})_{2}(2.0288(17) \AA)$, reflecting the strong trans influence of the sulfinate ligand. The arrangement of the acetate and the 4methylbenzenesulfinate about the palladium affords a close contact $(2.578(2) \AA$ ) between the nonbound $\mathrm{O}$ atom of the acetate and the 2-aryl-hydrogen of the 4-methylbenzenesulfinate.

Complex 7 then undergoes extrusion of $\mathrm{SO}_{2}$ to give complex $8\left(\delta_{\mathrm{P}}=18.50 \mathrm{ppm}\right)$ having a molecular formula of (4-Me$\left.\mathrm{C}_{6} \mathrm{H}_{4}\right) \mathrm{Pd}\left(\mathrm{PCy}_{3}\right)_{2}(\mathrm{OAc})$. The corresponding phenyl complex was reported and characterized by $\mathrm{X}$-ray crystallography by Eastgate and co-workers. ${ }^{21 \mathrm{a}}$ Above $100{ }^{\circ} \mathrm{C}$, complex 8 is then likely to undergo a second acetate/aryl sulfinate exchange to form a palladium sulfinate complex $\left(\mathrm{Ar}^{\prime}\right) \mathrm{Pd}\left(\mathrm{PCy}_{3}\right)_{2}\left(\mathrm{O}_{2} \mathrm{SAr}^{\prime}\right)$, followed by extrusion of $\mathrm{SO}_{2}$ and reductive elimination to generate a palladium zero intermediate and $4,4^{\prime}$-dimethylbiphenyl, the homocoupling product. Neither of these two intermediates were observed by NMR spectroscopy as the rate
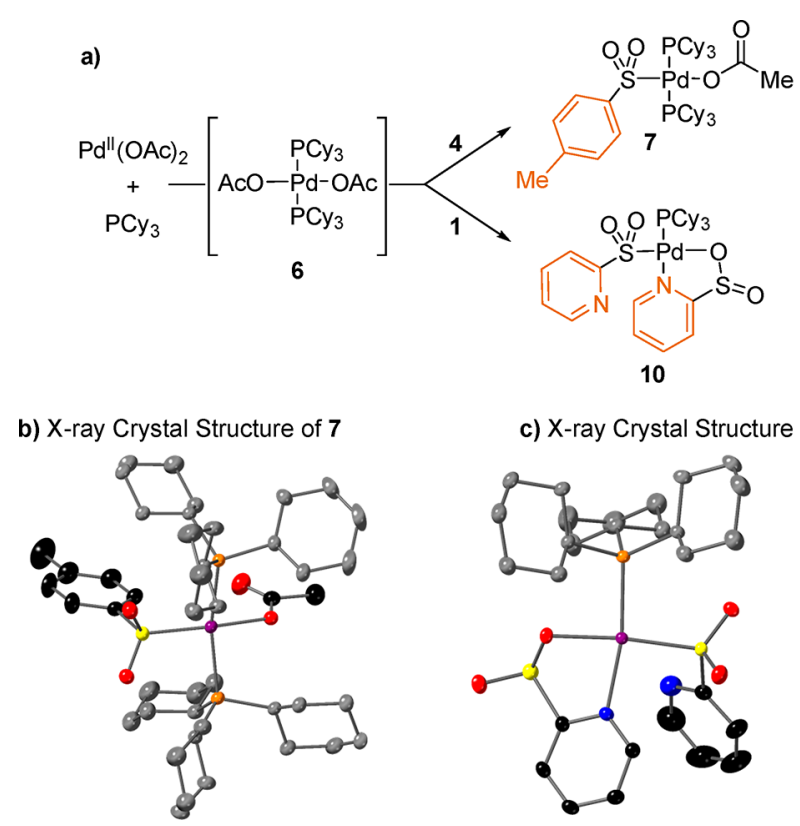

c) X-ray Crystal Structure of 10

Figure 2. (a) Synthesis of the palladium sulfinate complexes 7 and $\mathbf{1 0 .}$ X-ray crystal structures (50\% displacement ellipsoids) of (b) 7 and (c) 10. All $\mathrm{H}$ atoms have been omitted for the sake of clarity.

of extrusion of $\mathrm{SO}_{2}$ from such palladium sulfinate complexes (sections 2.2.3.2 and 2.5), and of oxidative addition (section 2.2.2), are expected to be fast at such temperatures. Instead, the oxidative addition complex $\left(4-\mathrm{F}-\mathrm{C}_{6} \mathrm{H}_{4}\right) \mathrm{Pd}\left(\mathrm{PCy}_{3}\right)_{2}(\mathrm{Br}) 9$ $\left(\delta_{\mathrm{P}}=20.08 \mathrm{ppm}\right)$ was observed. Complex 8 can also undergo an acetate/bromide exchange giving complex $\mathbf{8 b}\left(\delta_{\mathrm{P}}=19.79\right.$ $\mathrm{ppm})$, which can then undergo similar transformations leading to the formation of palladium zero and homocoupling product. Phosphine oxidation products were detected in trace amounts only, which is consistent with the observation that Pd$\left(\mathrm{PCy}_{3}\right)_{2}(\mathrm{OAc})_{2} 6$ is not easily reduced to palladium(0) via phosphine oxidation in the absence of hydroxide bases. ${ }^{21 a}$

When the cross-coupling was performed using 5-18 $\mathrm{mol} \%$ of $\mathrm{Pd}(\mathrm{OAc})_{2}$ and $\mathrm{PCy}_{3}$ in a 1:2 ratio, respectively, a linear correlation was observed between the amount of homocoupling product $\left(4,4^{\prime}\right.$-dimethylbiphenyl) formed and the amount of $\mathrm{Pd}(\mathrm{OAc})_{2}$ introduced (see the SI), which supports the proposed reduction pathway of the precatalyst.

When sodium pyridine-2-sulfinate 1 was employed as the nucleophilic coupling partner, a different palladium complex 10 was isolated (Figures $2 \mathrm{a}$ and $2 \mathrm{c}$ ). This complex also displays a square planar geometry around the $\mathrm{Pd}$ center, with a pyridine residue lying trans to the phosphine instead of a second phosphine ligand as in 7. Two 2-pyridyl sulfinate groups are present in 10. One chelates the palladium in a $\kappa_{\mathrm{N}, \mathrm{O}}^{2}$-mode, affording a five-membered metallocycle. This mode of ligand binding has precedence in copper 2-pyridyl sulfinate complexes. $^{31}$ The second 2-pyridyl sulfinate coordinates the palladium by the sulfur, trans to the oxygen binding. The $\mathrm{Pd}-\mathrm{S}$ bond length in 10 (2.2307(5) $\AA$ ) is notably shorter than that in 7 , possibly reflecting the decreased steric congestion in the former.

2.2.2. Oxidative Addition Complex. Once the active $\operatorname{Pd}(0)$ species have been generated, the next step of the presumed mechanism is the oxidative addition of the carbon-halide bond to the $\operatorname{Pd}(0)$ intermediate. Oxidative addition of bromobenzene to $\mathrm{Pd}\left(\mathrm{PCy}_{3}\right)_{2}$ has been investigated by Baird 
and co-workers ${ }^{32}$ and Hartwig and co-workers. ${ }^{33}$ Although these studies were conducted in nonpolar solvents and at room temperature, both concluded that the oxidative addition was an irreversible process that involved the aryl bromide substrate and the two-coordinate palladium zero complex $\mathrm{Pd}\left(\mathrm{PCy}_{3}\right)_{2}$, leading to the formation of compounds with the generic formula $(\mathrm{Ar}) \mathrm{Pd}\left(\mathrm{PCy}_{3}\right)_{2}(\mathrm{Br})$. The oxidative addition complex (4-F- $\left.\mathrm{C}_{6} \mathrm{H}_{4}\right) \mathrm{Pd}\left(\mathrm{PCy}_{3}\right)_{2}(\mathrm{Br}) 9$ was synthesized independently, according to literature procedures, ${ }^{34}$ and proved to be a competent catalyst for our sulfinate coupling reactions, giving similar reaction rate and yield, compared to the mixture of $\mathrm{Pd}(\mathrm{OAc})_{2}$ and $\mathrm{PCy}_{3}$ (see the $\mathrm{SI}$ ).

2.2.3. Palladium Sulfinate Complexes. For cross-coupling processes in general, the transmetalation step, which involves the oxidative addition complex and the nucleophilic coupling partner, differs for each nucleophile, leading to a wide variety of mechanisms and palladium intermediates. Such posttransmetalation complexes have been characterized for several nucleophiles, including alcohols, ${ }^{35}$ amines, ${ }^{36}$ thiols, ${ }^{37}$ and carboxylic acids. ${ }^{38}$ However, despite having been reported as efficient coupling partners, to the best of our knowledge, there is no report of a post-transmetalation intermediate with a nucleophilic sulfinate. A dimeric palladium sulfinate complex with bridging $\mathrm{Cl}^{-}$anions has recently been reported by Shavnya and co-workers; ${ }^{39}$ however, it is not relevant to an oxidative addition/transmetalation sequence. In the studied cross-coupling, putative palladium sulfinate intermediates would arise from the displacement of the $\mathrm{Br}$ atom from oxidative addition complex 9 by a metal sulfinate salt, as described in Scheme 3.

\section{Scheme 3. Putative Formation of the Palladium Sulfinate} Complexes

$(\mathrm{Ar}) \mathrm{Pd}\left(\mathrm{PC} \mathrm{y}_{3}\right)_{n}(\mathrm{Br})+\mathrm{MO}_{2} \mathrm{SAr}^{\prime} \rightarrow(\mathrm{Ar}) \mathrm{Pd}\left(\mathrm{PC}_{3}\right)_{n}\left(\mathrm{O}_{2} \mathrm{SAr} r^{\prime}\right)+\mathrm{M}-\mathrm{Br}$

Unlike carboxylate salts, metal sulfinate complexes can have different coordination modes, binding through sulfur, oxygen, or both. ${ }^{40}$ In the previous section, we have described two types of palladium sulfinate complexes relevant to the reduction of $\operatorname{Pd}(\mathrm{II})$ to $\mathrm{Pd}(0)$. In the following section, we describe the first synthesis and characterization of post-transmetalation aryl palladium sulfinate complexes.

2.2.3.1. Synthesis and Characterization. We first attempted to form the transmetalation complexes by heating the oxidative addition complex 9 at moderate to elevated temperatures $\left(50-120^{\circ} \mathrm{C}\right)$ in the presence of the carbocyclic sulfinate salt 4. However, formation of biaryl 5 and/or decomposition were observed. In the presence of silver nitrate, the oxidative addition complex was entirely consumed at room temperature, and we isolated the dimeric palladium sulfinate complex 11 (Figures 3a and 3b). When the pyridine-2-sulfinate substrate 1 was subjected to the same reaction conditions, the monomeric palladium sulfinate complex 12 was obtained (Figures $3 \mathrm{a}$ and $3 \mathrm{c}$ ). The geometry about the palladium center in 12 closely resembles that present in 10. The $\mathrm{Pd}-\mathrm{O}$ bond length in complex $12(2.132(2) \AA)$ is elongated, relative to that in complex $10(2.0975(13) \AA)$, reflecting the greater trans influence of the aryl ligand. A similar square planar geometry about the palladium is observed in complex 11; however, the absence of a pyridyl substituent on the sulfinate results in the vacant site being occupied by the $S$ atom of a neighboring

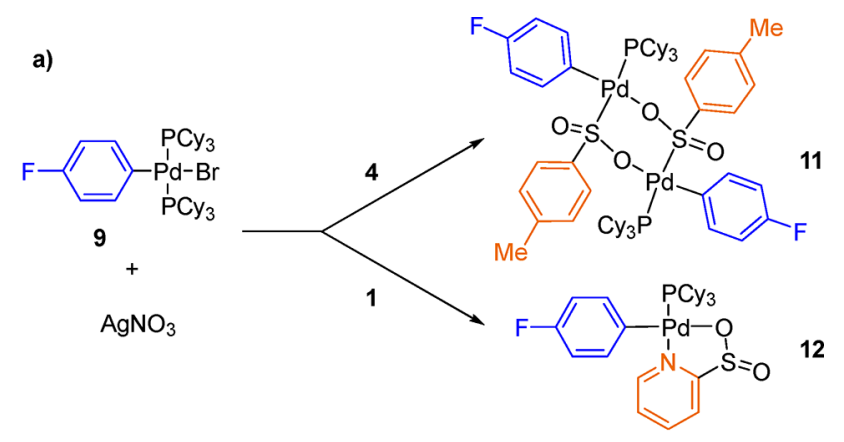

b) X-ray Crystal Structure of 11

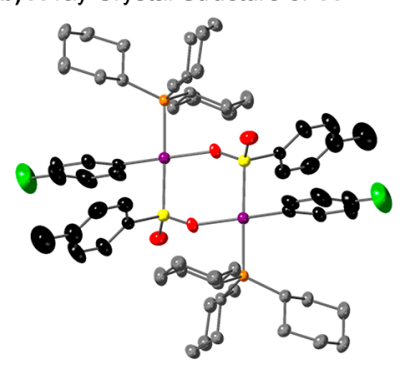

c) X-ray Crystal Structure of 12

d) X-ray Crystal Structure of $\mathbf{1 3}$
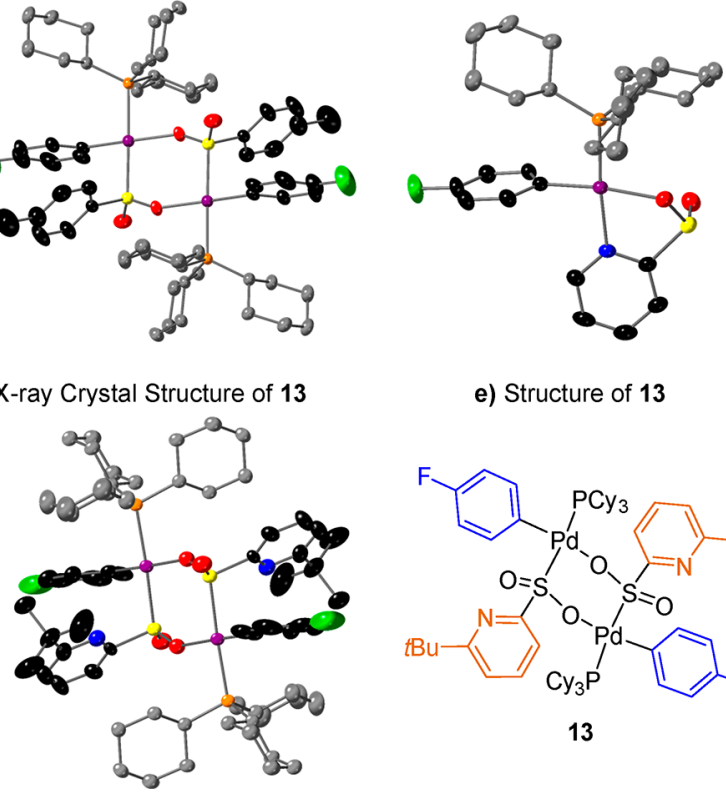

e) Structure of 13

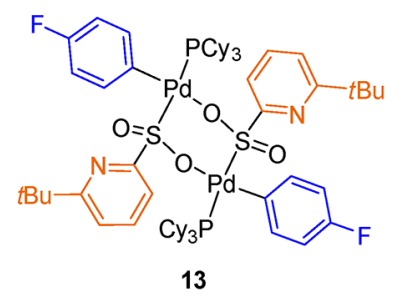

Figure 3. (a) Synthesis of the palladium sulfinate complexes 11 and 12. X-ray crystal structures (50\% displacement ellipsoids) of (b) 11, (c) 12, and (d) 13. (e) Structure of 13. All $\mathrm{H}$ atoms have been omitted for the sake of clarity.

sulfinate, affording a dimeric structure. The structure is similar to that of $\left[\left(\mathrm{PMe}_{3}\right) \mathrm{Pd}\left(\mathrm{CH}_{2} \mathrm{CMe}_{2} \mathrm{C}_{6} \mathrm{H}_{4} \mathrm{SO}_{2}\right)\right]_{2}$, which likewise features a trans-phosphorus-sulfur configuration. ${ }^{41}$ The bond lengths and angles observed in $\mathbf{1 1}$ also resemble those in $\left[\left(\mathrm{PMe}_{3}\right) \mathrm{Pd}\left(\mathrm{CH}_{2} \mathrm{CMe}_{2} \mathrm{C}_{6} \mathrm{H}_{4} \mathrm{SO}_{2}\right)\right]_{2}$.

The diffusion coefficients obtained by DOSY NMR spectroscopy predicted masses for complexes 11 and 12 in a 2:1 ratio, indicating that the former maintains its dimeric structure in solution. The degree of aggregation in these complexes is also maintained when either an electron-donating or electron-withdrawing substituent is introduced at the position para to the sulfinate group (see the SI).

A notable exception is when steric bulk, in the form of a tertbutyl group, is placed at the 6-position of the pyridine. This prevents the $\kappa^{2}{ }_{\mathrm{N}, \mathrm{O}}$-binding mode of the pyridine sulfinate, thereby affording a dimeric solid-state structure 13 which resembles that of the 4-methylbenzenesulfinate substituted complex, 11 (Figure 3d). X-ray-suitable crystals could be obtained from $\mathrm{CH}_{2} \mathrm{Cl}_{2}$ /hexane recrystallization of crude reaction mixtures; however, attempts to obtain analytically pure samples for this compound were unsuccessful.

2.2.3.2. Reactivity. When the dimeric complex 11 was subjected to 1.1 equiv of $\mathrm{PCy}_{3}$, its resonance peak at $\delta_{\mathrm{P}}=27.77$ ppm disappeared and was replaced by a doublet at $\delta_{\mathrm{P}}=21.95$ 


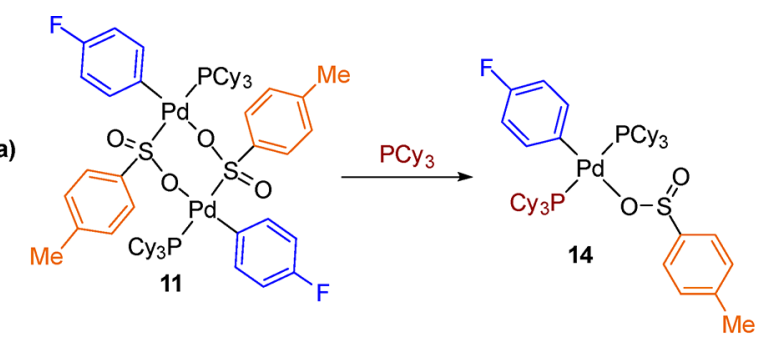

b) X-ray Crystal Structure of 14

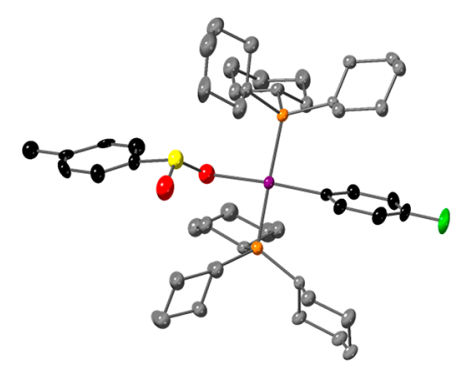

b)

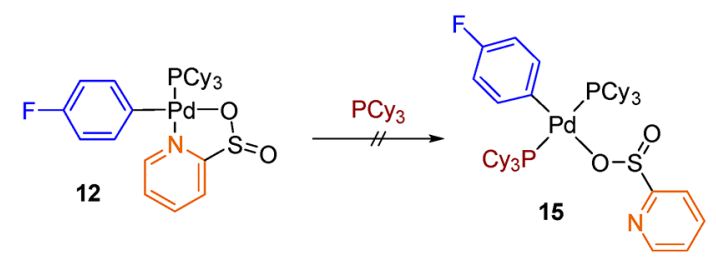

c)

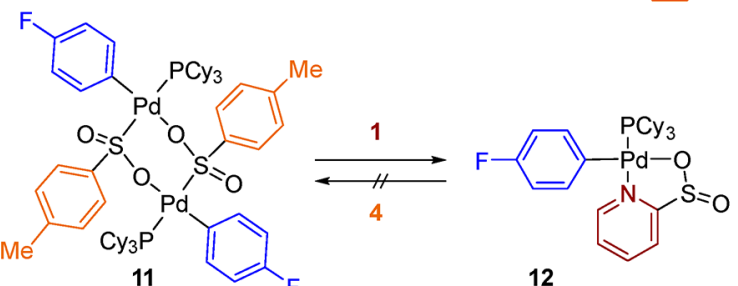

12

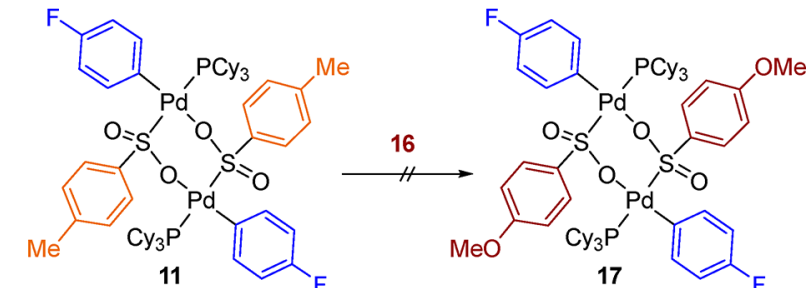

e)
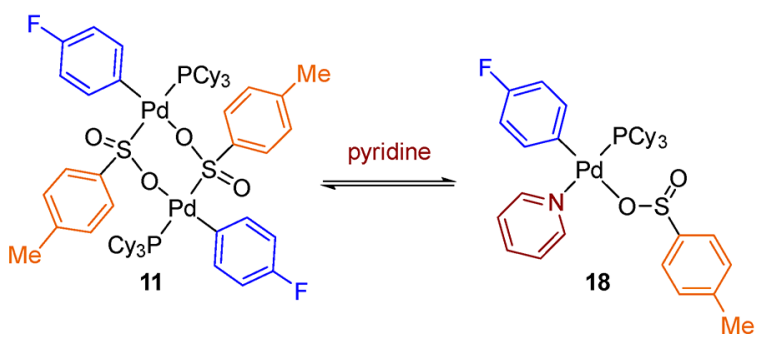

Figure 4. Reactivity of the palladium sulfinate complexes 11 and 12 at room temperature in 1,4-dioxane/benzene- $d_{6}$ 5:1. X-ray crystal structure (50\% displacement ellipsoids) of 14. All $\mathrm{H}$ atoms have been omitted for the sake of clarity. $16=4-\mathrm{MeO}-\mathrm{C}_{6} \mathrm{H}_{4}-\mathrm{SO}_{2} \mathrm{Na}$.

$\mathrm{ppm}, \mathrm{J}_{\mathrm{P}-\mathrm{F}}=3.0 \mathrm{~Hz}$. This new signal is very similar to the resonance peak observed for the oxidative addition complex 9 $\left(\delta_{\mathrm{P}}=20.20, \mathrm{~J}_{\mathrm{P}-\mathrm{F}}=3.0 \mathrm{~Hz}\right)$. Although the conversion was quantitative according to the ${ }^{19} \mathrm{~F}\left\{{ }^{1} \mathrm{H}\right\}$ NMR spectrum, the new complex was only isolated in $57 \%$ yield. Crystals suitable for $\mathrm{XRD}$ were obtained, and the identity of complex 14 was confirmed as a square planar palladium complex bearing two phosphine ligands (Figure 4a). The solid-state structure of 14 closely resembles that of 7 ; however, unlike in the latter, the sulfinate binds to palladium via the $\mathrm{O}$ atom, rather than a $\mathrm{S}$ atom. This is consistent with a nucleophilic displacement of the $S$ atom from dimeric complex 11. While the addition of a phosphine to the dimeric complex 11 occurs at room temperature, the pyridine sulfinate containing palladacycle $\mathbf{1 2}$ was unreactive toward $\mathrm{PCy}_{3}$, and compound 15 was not observed, suggesting that the $\mathrm{Pd}-\mathrm{N}$ bond in 12 is much stronger than the $\mathrm{Pd}-\mathrm{S}$ bond in dimeric complex 11 (Figure 4b). Accordingly, formation of complex 12 was observed at room temperature upon combining dimeric complex 11 and sodium pyridine-2-sulfinate 1 , whereas the reverse reaction was not observed under the same conditions (Figure 4c). Exchange between two carbocyclic sulfinates was not observed at room temperature either, as dimeric complex 17 was not observed when the more nucleophilic 4-methoxybenzene-sulfinate salt 16 was combined with dimeric complex 11 (Figure 4d). However, the $\mathrm{Pd}-\mathrm{S}$ bond of $\mathbf{1 1}$ could be cleaved upon addition of excess pyridine (Figure 4e). A new complex was observed by NMR spectroscopy and assigned as complex 18, but its isolation was not possible, since $\mathbf{1 1}$ was recovered after workup.

When 4-methylbenzenesulfinate palladium complex 11 was heated at $90{ }^{\circ} \mathrm{C}$ in toluene- $d_{8}$, it was fully consumed within 20 min with concomitant formation of biaryl 5 (Figure 5, gray diamonds). Complex 14 (generated in situ from 11 and $\mathrm{PCy}_{3}$ ) reacted at a slower rate, but gave $84 \%$ conversion within 45 min (Figure 5, yellow triangles). Increasing the concentration of $\mathrm{PCy}_{3}$ resulted in a significant decrease of the rate of $\mathrm{SO}_{2}$ extrusion at $90{ }^{\circ} \mathrm{C}$, suggesting that ligand dissociation is necessary prior to desulfination (see the SI). The pyridine-2sulfinate palladacycle $\mathbf{1 2}$ in which the sulfinate chelates the palladium in a $\kappa_{\mathrm{N}, \mathrm{O}}^{2}$-mode only gave $11 \%$ conversion after 45
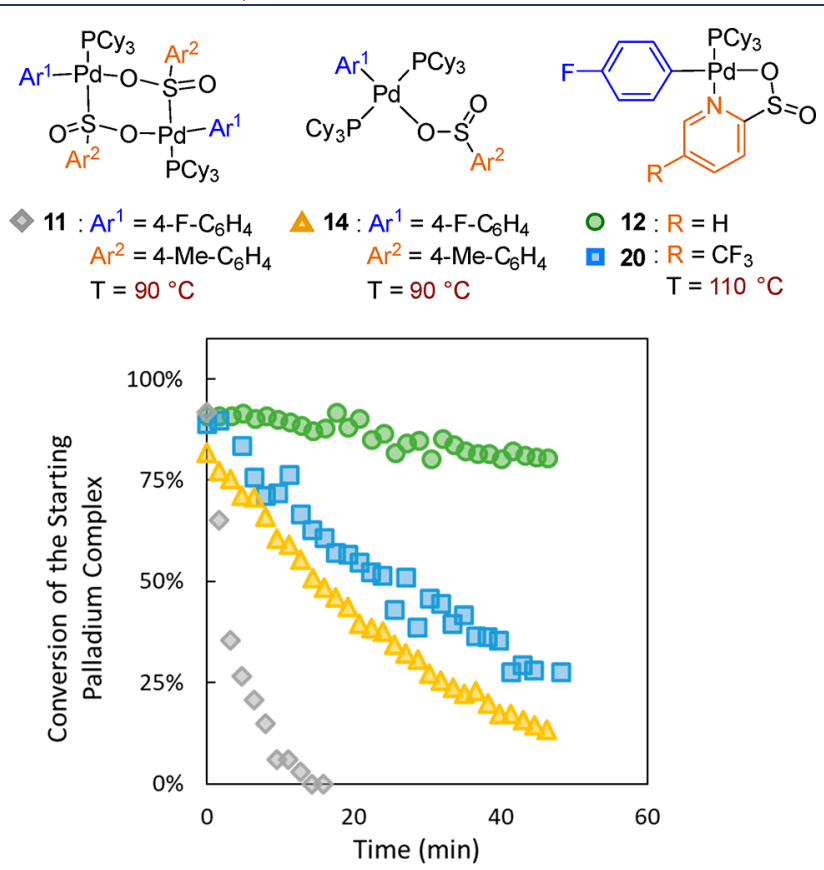

Figure 5. Reactivity of the palladium sulfinate complexes upon heating. Reactions were performed in toluene- $d_{8}$ in a Young's NMR tube. Complex 14 was generated in situ from complex 11 and tricyclohexylphosphine. 
min at $110^{\circ} \mathrm{C}$ (Figure 5, green circles). Weakening the $\mathrm{Pd}-\mathrm{N}$ bond by adding an electron-withdrawing group on the pyridyl ring, as in complex 20, increased the rate of extrusion of $\mathrm{SO}_{2}$ in toluene- $d_{8}$, as a $70 \%$ conversion was obtained after $45 \mathrm{~min}$ at $110{ }^{\circ} \mathrm{C}$ (Figure 5, blue squares). The relative rates of consumption of the complexes shown in Figure 5 have been shown to correspond to the rates of formation of the crosscoupling products (see the SI).

Overall, these experiments show that the S-Pd bond present in dimer 11 can readily be displaced by nitrogen- or phosphorus-based nucleophiles. The formation of fivemembered-ring palladacycles with the pyridine-2-sulfinate substrates renders the derived palladium sulfinate complexes more thermodynamically stable, and dramatically slows the extrusion of $\mathrm{SO}_{2}$. In addition, we have shown that complexes 11, 12, and 14 are competent catalysts for their respective coupling reactions (see the SI).

2.3. Identification of the Resting-State Intermediates. To identify the resting-state intermediates of the catalytic reactions, the desulfinative cross coupling was monitored by ${ }^{31} \mathrm{P}\left\{{ }^{1} \mathrm{H}\right\} \mathrm{NMR}$ and ${ }^{19} \mathrm{~F}\left\{{ }^{1} \mathrm{H}\right\}$ NMR spectroscopy. The reactions were performed in a Young's NMR tube with a higher loading of $\mathrm{Pd}(\mathrm{OAc})_{2}$ and $\mathrm{PCy}_{3}(15 \mathrm{~mol} \%$ and $30 \mathrm{~mol} \%$, respectively). The observed resonance peaks were compared to the signals of reference samples acquired in a 5:1 mixture of 1,4-dioxane/ benzene- $d_{6}$. Because of poor stirring of the heterogeneous mixture in an NMR tube, the reaction kinetics were found to be very slow. After $14 \mathrm{~h}$ at $150{ }^{\circ} \mathrm{C}$, at which point biaryl 5 was formed in $40 \%$ yield ( 2.7 turnovers), the resonance peak of the oxidative addition complex $9\left(\delta_{\mathrm{F}}=-124.26 \mathrm{ppm}\right)$ was the only other signal observed on the ${ }^{19} \mathrm{~F}\left\{{ }^{1} \mathrm{H}\right\}$ spectrum along with starting material, internal standard, and product (Figure 6a). The corresponding characteristic doublet at $\delta_{\mathrm{P}}=20.08 \mathrm{ppm}$ was also observed in the ${ }^{31} \mathrm{P}\left\{{ }^{1} \mathrm{H}\right\}$ spectrum, along with free $\mathrm{PCy}_{3}\left(\delta_{\mathrm{P}}=9.24 \mathrm{ppm}\right)$, phosphine oxide $\left(\delta_{\mathrm{P}}=45.65 \mathrm{ppm}\right)$ and compound $8\left(\delta_{\mathrm{p}}=19.80 \mathrm{ppm}\right)$ (Figure $\left.6 \mathrm{c}\right)$. Therefore, the oxidative addition complex 9 is likely to be the resting-state intermediate when using carbocyclic sulfinate 4 . The same experiment was performed with the pyridine-2-sulfinate substrate 1 . After $14 \mathrm{~h}$ of reaction at $150{ }^{\circ} \mathrm{C}$, the conversion to product 3 was lower than for the carbocyclic substrate (20\%, $\sim 1.3$ turnovers). The oxidative addition product 9 was observed in a 1:1 ratio with palladium sulfinate complex 12 (Figure 6b). The corresponding phosphorus resonance peaks $\left(\delta_{\mathrm{P}}=38.03\right.$ and $\left.\delta_{\mathrm{P}}=20.08\right)$, along with free $\mathrm{PCy}_{3}$ oxidation products, were also observed (Figure $6 \mathrm{~d}$ ).

In section 2.2.3.2, we have assessed the reactivity of the palladium sulfinate complexes and demonstrated that weakening of the $\mathrm{N}-\mathrm{Pd}$ bond facilitates the extrusion of $\mathrm{SO}_{2}$ from the palladium pyridine-2-sulfinate complexes. When sodium 5(trifluoromethyl)pyridine-2-sulfinate 19 was subjected to the cross-coupling conditions in a Young's NMR tube, the corresponding palladium sulfinate complex 20 could not be detected by ${ }^{19} \mathrm{~F}\left\{{ }^{1} \mathrm{H}\right\}$ or ${ }^{31} \mathrm{P}\left\{{ }^{1} \mathrm{H}\right\}$ NMR, and the oxidative addition complex 9 was the only observable complex by ${ }^{19} \mathrm{~F}\left\{{ }^{1} \mathrm{H}\right\}$ NMR spectrum (see the SI). Similarly, sodium pyridine-4-sulfinate $\mathbf{2 1}$, which does not have the appropriate substitution pattern to form a stabilizing $\mathrm{N}-\mathrm{Pd}$ interaction, only exhibited the resonance of the oxidative addition complex 9 (see the SI). Unidentified minor resonances were detected at $\delta_{\mathrm{P}}=19.81 \mathrm{ppm}$ and $\delta_{\mathrm{P}}=20.17 \mathrm{ppm}$, together with free ligand and minor phosphine oxide peaks. Finally, the oxidative addition complex 9 was once again the only resonance observed in the ${ }^{19} \mathrm{~F}\left\{{ }^{1} \mathrm{H}\right\}$ spectrum when the bulky lithium 6(tert-butyl)pyridine-2-sulfinate $\mathbf{2 2}$ was used. This is consistent with the observation of the dimeric crystal structure of the 6tert-butylsulfinate containing palladium complex 13, as the formation of a $\kappa_{\mathrm{N}, \mathrm{O}}^{2}$-chelate is hindered by the tert-butyl group, showing that the bulky pyridine sulfinate salt behaves in a manner similar to that of a carbocyclic substrate.

Since the concentration, stirring, and therefore kinetics in an NMR tube are not accurately representative of the actual reaction conditions, the two cross-coupling reactions involving sodium pyridine-2-sulfinate 1 and sodium 4-methylbenzenesulfinate $\mathbf{4}$ were also performed in microwave tubes at a relevant scale. The tubes were heated for $2 \mathrm{~h}$ at $150{ }^{\circ} \mathrm{C}$, then $500 \mu \mathrm{L}$ of the reaction mixture were transferred to an NMR tube containing $100 \mu \mathrm{L}$ of benzene- $d_{6}$. The observed resonance peaks were in agreement with the reactions performed in the Young's NMR tubes. One difference was observed for the cross-coupling of pyridine-2-sulfinate salt $\mathbf{1}$ for which the ratio between the oxidative addition complex 9 and the pyridine sulfinate complex 12 was found to be 1:3.8 instead of $1: 1$ (see the SI). The use of an appropriate reaction vial equipped with a stirrer bar instead of Young's NMR tube must ease the transmetalation step, which involves the poorly soluble sulfinate salt, while the rate of extrusion of $\mathrm{SO}_{2}$ remains unaffected and difficult, because of the strong $\kappa_{\mathrm{N}, \mathrm{O}^{-}}^{2}$ chelation mode. As a consequence, the resting-state intermediate is shifted from the oxidative addition complex 9 to the pyridine2-sulfinate containing palladium complex 12 .

Overall, these experiments show that the resting state of the catalyst is highly dependent on the nature of the sulfinate coupling partner and is more likely to be the oxidative addition
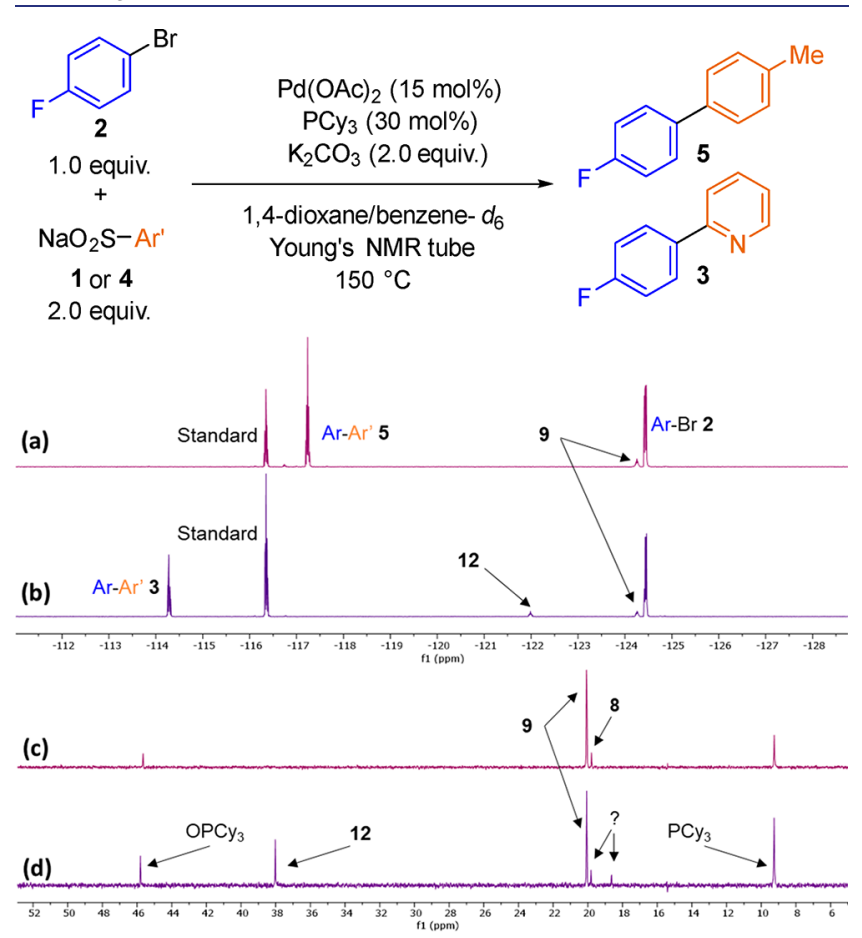

Figure 6. Cross-coupling reactions performed in a Young's NMR tube. (a) ${ }^{19} \mathrm{~F}\left\{{ }^{1} \mathrm{H}\right\}$ NMR spectrum of the reaction mixture involving sulfinate 4. (b) ${ }^{19} \mathrm{~F}\left\{{ }^{1} \mathrm{H}\right\}$ NMR spectrum of the reaction mixture involving sulfinate 1. (c) ${ }^{31} \mathrm{P}\left\{{ }^{1} \mathrm{H}\right\}$ NMR spectrum of the reaction mixture involving sulfinate 4. (d) ${ }^{31} \mathrm{P}\left\{{ }^{1} \mathrm{H}\right\}$ NMR spectrum of the reaction mixture involving sulfinate $\mathbf{1}$. 

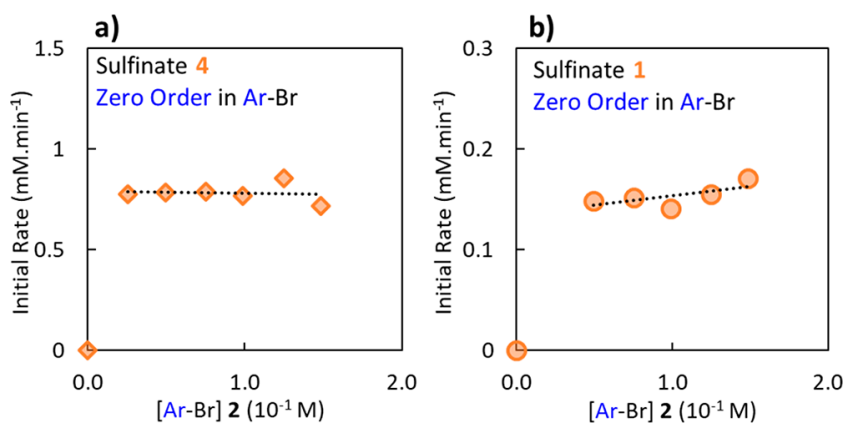

Figure 7. Initial rate plots for cross coupling between aryl bromide 2 and (a) sodium 4-methylbenzenesulfinate 4 (orange diamonds) and (b) sodium pyridine-2-sulfinate 1 (orange circles).
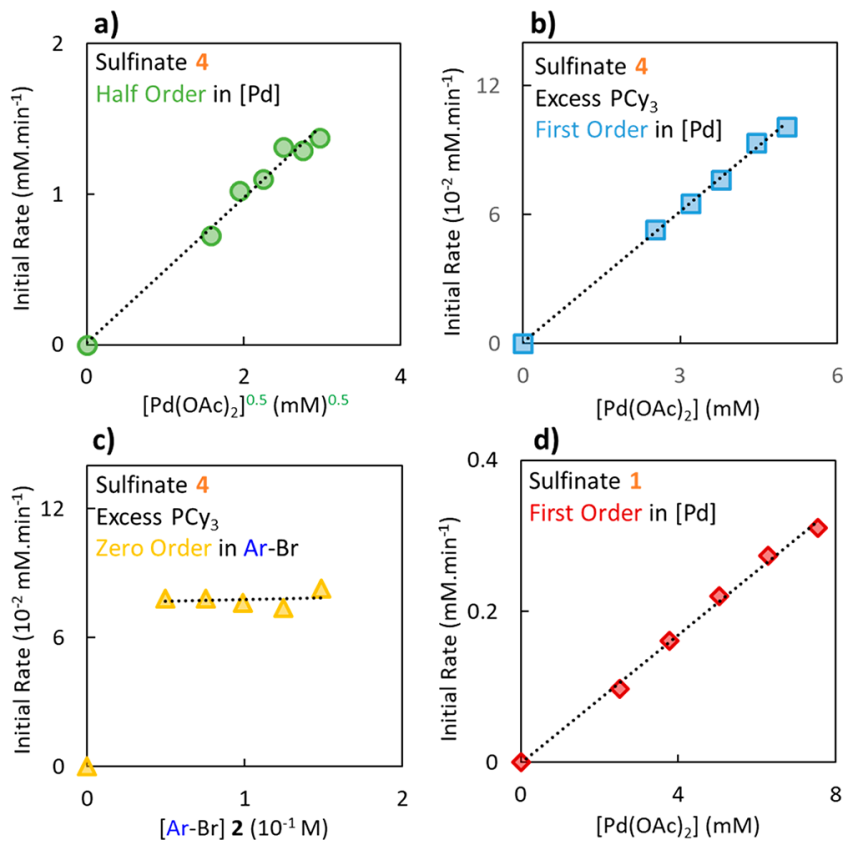

Figure 8. Initial rate plots for cross coupling between aryl bromide 2 and (a) 4-methylbenzenesulfinate 4 (green circles), (b) 4-methylbenzenesulfinate 4 using an excess of $\mathrm{PCy}_{3}$ (blue squares), (c) 4methylbenzenesulfinate 4 using an excess of $\mathrm{PCy}_{3}$ (gold triangles), and (d) pyridine-2-sulfinate 1 (red diamonds).

complex 9 for carbocyclic sulfinates or for pyridine-sulfinate substrates that cannot form strong $\mathrm{N}-\mathrm{Pd}$ bonds, due to geometrical, steric, or electronic reasons. A strong $\kappa^{2}{ }_{\mathrm{N}, \mathrm{O}^{-}}$ chelation as observed for the unsubstituted pyridine-2-sulfinate group in the palladium sulfinate complex $\mathbf{1 2}$ was observed to cause a change in the resting-state intermediate.

2.4. Initial Rate Studies. Productive catalytic reactions are performed at $150{ }^{\circ} \mathrm{C}$ in 1,4-dioxane (boiling point (bp) $=101$ ${ }^{\circ} \mathrm{C}$ ) and involve partially soluble reagents such as the sulfinate salts and potassium carbonate, leading to suspensions rather than homogeneous solutions. Therefore, the reactions could not be accurately monitored by NMR spectroscopy and were monitored using HPLC analysis of aliquots taken from the reaction mixture via syringe, and the partial orders were obtained using the initial rates of the reactions.

2.4.1. Order in Aryl Bromide. The reactions of 4methylbenzenesulfinate 4 and pyridine-2-sulfinate 1 were performed with different concentrations of aryl bromide $\mathbf{2}$ (0.025-0.15 mM).
The initial rates were not affected by the concentration of the electrophilic coupling partner (Figures $7 a$ and $7 b$ ). This zero-order behavior suggests that oxidative addition of the $\mathrm{C}-$ $\mathrm{Br}$ bond into the $\mathrm{Pd}(0)$ species is not the turnover limiting step under the reaction conditions. This observation is in agreement with the observed resting-state intermediates in section 2.3.

2.4.2. Order in Sulfinate Salt and $\mathrm{K}_{2} \mathrm{CO}_{3}$. It was observed that $0.010-0.10 \mathrm{M}$ solutions of sodium 4-methylbenzenesulfinate 4 or sodium pyridine-2-sulfinate 1 are heterogeneous at $150{ }^{\circ} \mathrm{C}$. Therefore, the partial orders in sulfinate coupling partner were not measured. Similarly, the order in potassium carbonate was not obtained.

2.4.3. Order in Catalyst. To get the partial order in catalyst, the initial rate of the reaction was measured for different concentrations of $\mathrm{Pd}(\mathrm{OAc})_{2}$ and $\mathrm{PCy}_{3}$, keeping the ligand to palladium ratio fixed at two. The rate of the reaction involving 4-methylbenzenesulfinate sodium salt 4 was observed to be approximately proportional to the square root of the total concentration of palladium introduced, as palladium acetate: rate $\propto\left[\mathrm{Pd}(\mathrm{OAc})_{2}\right]^{0.5}$ (Figure $\left.8 \mathrm{a}\right)$. Half order in catalyst can generally be rationalized by an equilibrium between a catalytically active complex and an off-cycle species. This can be caused by dimerization of the active catalyst to form an inactive dimer. ${ }^{42}$ Half-order dependence of the catalyst can also arise from ligand dissociation. ${ }^{43}$ When the concentration of $\mathrm{Pd}(\mathrm{OAc})_{2}$ was varied while the phosphine ligand was in excess, such as $\left[\mathrm{Pd}(\mathrm{OAc})_{2}\right] /\left[\mathrm{PCy}_{3}\right]<0.10$, the half-order dependence on the concentration of palladium acetate was no longer observed. Instead, the rate was observed to be directly proportional to the concentration of $\mathrm{Pd}(\mathrm{OAc})_{2}$ : rate $\propto$ $\left[\mathrm{Pd}(\mathrm{OAc})_{2}\right]$ (Figure $\left.8 \mathrm{~b}\right)$.

Therefore, the half-order dependence observed can be taken into account by a fast equilibrium between the catalytically inactive oxidative addition intermediate $(\mathrm{Ar}) \mathrm{Pd}\left(\mathrm{PCy}_{3}\right)_{2}(\mathrm{Br})$ and the reactive intermediate $(\mathrm{Ar}) \mathrm{Pd}\left(\mathrm{PCy}_{3}\right)(\mathrm{Br})$ generated after the loss of a phosphine ligand (Scheme 4). However, the rate of oxidative addition is known to decrease dramatically upon the addition of ligand, as the inactive tris-ligated $\mathrm{Pd}^{0}\left(\mathrm{PCy}_{3}\right)_{3}$ can be formed. ${ }^{44}$ In order to verify that the switch between half-order and first-order is not due to a change of turnover-limiting step, the order in aryl bromide was determined for a $\mathrm{Pd} / \mathrm{L}$ ratio $<0.10$ (Figure $8 \mathrm{c}$ ). A zero-order case was obtained under these conditions, showing that the oxidative addition is not rate-determining in the presence of excess ligand.

\section{Scheme 4. Interpretation of the Initial Rates for the Carbocyclic Sulfinate 4}

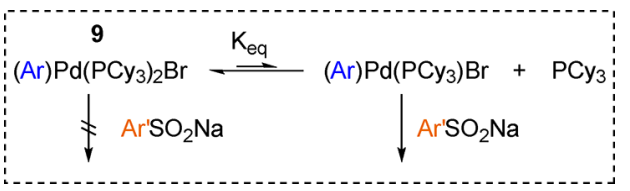

In order to assess the lability of $\mathrm{PCy}_{3}$ under the reaction conditions, the analogous oxidative addition complex 23 was synthesized with the electronically and sterically similar triisopropylphosphine $\mathrm{P}$ - $\mathrm{Pr}_{3}{ }^{45}$ When the two oxidative addition complexes were heated at $75{ }^{\circ} \mathrm{C}$ in a 5:1 mixture of 1,4 dioxane/benzene- $d_{6}$, statistical scrambling was obtained within $2 \mathrm{~h}$ and the mixed complex $\mathbf{2 4}$ was observed (Scheme 5). 
Scheme 5. Lability of $\mathrm{PCy}_{3}$ under the Reaction Conditions

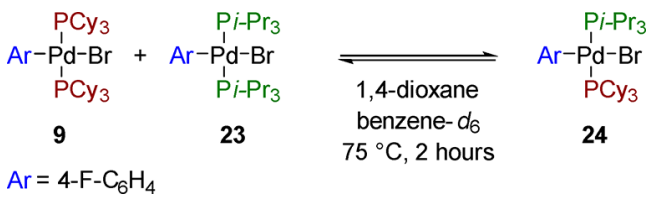

Therefore, $\mathrm{PCy}_{3}$ is likely to be labile under the reaction conditions, which supports the phosphine dissociation/transmetalation sequence.

The rate of the reaction involving sodium pyridine-2sulfinate 1 was directly proportional to the concentration of palladium acetate: rate $\propto\left[\mathrm{Pd}(\mathrm{OAc})_{2}\right]$ (Figure $\left.8 \mathrm{~d}\right)$. There is no longer a half-order dependence in $\mathrm{Pd}(\mathrm{OAc})_{2}$ as observed for the carbocyclic sulfinate 4 . This is in agreement with the observation of different resting-state intermediates for reactions involving substrates 1 and 4 . For the former, the first order dependence in $\mathrm{Pd}(\mathrm{OAc})_{2}$ is consistent with the catalyst resting state being palladium sulfinate complex 12 and the rate-determining step being the extrusion of $\mathrm{SO}_{2}$. As a halforder dependency is not observed for pyridine-2-sulfinate $\mathbf{1}$, this suggests that the transmetalation is irreversible under these reaction conditions.

2.5. Comparison of the Rates of Transmetalation and $\mathrm{SO}_{2}$ Extrusion. Stoichiometric reactions involving the oxidative addition complex 9 or the palladium sulfinate complexes 11 and 12 were performed in order to qualitatively compare the rates of transmetalation and extrusion of $\mathrm{SO}_{2}$. For the reaction involving the oxidative addition complex 9, 2 equiv of the potassium sulfinate salts $\mathbf{2 5}$ or $\mathbf{2 6}$ were employed (Figure 9). The potassium salts were chosen for these stoichiometric studies, since evidence suggests that these are the salts formed in the catalytic reactions when $\mathrm{K}_{2} \mathrm{CO}_{3}$ is used as the base (section 2.6.2). When the dimeric complex 11 was heated at $150{ }^{\circ} \mathrm{C}$ with $1-4$ equiv of $\mathrm{PCy}_{3}$, with respect to the amount of palladium, full conversion to the corresponding biaryl 5 was obtained within 2 min (Figure 9a). Although we have demonstrated that added phosphine slows the rate of extrusion of $\mathrm{SO}_{2}$ at $90{ }^{\circ} \mathrm{C}$ in toluene- $d_{6}$ (see the $\mathrm{SI}$ ), these data show that the concentration of ligand does not affect the rate of extrusion of $\mathrm{SO}_{2}$ from the in-situ-generated complex 14 at $150{ }^{\circ} \mathrm{C}$. However, the rate of the transmetalation $/ \mathrm{SO}_{2}$ extrusion sequence was dramatically slowed upon the addition of $\mathrm{PCy}_{3}$ (Figure 9b). An excess of phosphine is likely shifting the equilibrium between the transmetalation inactive ( $\mathrm{Ar}) \mathrm{Pd}$ $\left(\mathrm{PCy}_{3}\right)_{2}(\mathrm{Br}) 9$ and the transmetalation active $(\mathrm{Ar}) \mathrm{Pd}\left(\mathrm{PCy}_{3}\right)-$ $\mathrm{Br}$ ) toward 9, slowing the overall rate of product formation. These observations are consistent with a turnover-limiting transmetalation after the loss of ligand from oxidative addition complex 9, as exposed in section 2.4.3.

For pyridine-2-sulfinate palladium complex 12, the rate of extrusion of $\mathrm{SO}_{2}$ was much slower than for carbocyclic complex 11 (Figure 9c). Indeed, independent of the concentration of ligand, at least $20 \mathrm{~min}$ were necessary to reach $>90 \%$ conversion, compared to $<2 \mathrm{~min}$ for the carbocyclic system. The concentration of ligand did not affect the rate of $\mathrm{SO}_{2}$ extrusion at $150{ }^{\circ} \mathrm{C}$. Compared to the reaction with the carbocyclic sulfinate in Figure $9 \mathrm{~b}$, ligand concentration had little impact on the observed rate of product formation for the transmetalation/extrusion of $\mathrm{SO}_{2}$ sequence with potassium pyridine-2-sulfinate 26 (Figure 9d). This is consistent with the rate-determining step of the trans-
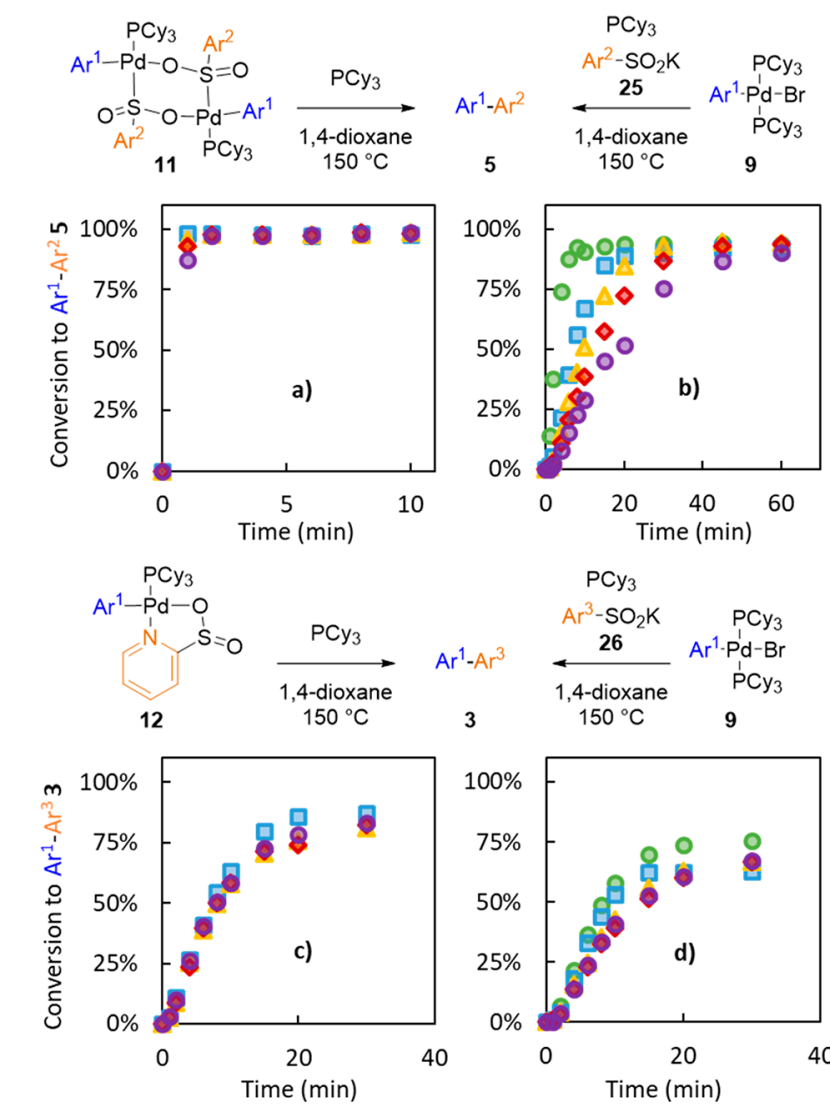

Figure 9. Comparison of the rates of the $\mathrm{SO}_{2}$ extrusion and of the sequence of transmetalation/ $\mathrm{SO}_{2}$ extrusion for both carbocyclic sulfinate 4 and pyridine-2-sulfinate 1 . $\mathrm{Pd}_{\text {total }}$ (1.0 equiv), $\mathrm{PCy}_{3}(0-4.0$ equiv), $\mathrm{Ar}^{2} \mathrm{SO}_{2} \mathrm{~K}$ (2.0 equiv), $\mathrm{Ar}^{3} \mathrm{SO}_{2} \mathrm{~K}$ (2.0 equiv). $\mathrm{Ar}^{1}=4-\mathrm{F}_{-} \mathrm{C}_{6} \mathrm{H}_{4}$; $\mathrm{Ar}^{2}=4-\mathrm{Me}-\mathrm{C}_{6} \mathrm{H}_{4} ; \mathrm{Ar}^{3}=2$-pyridyl. [Legend: green circles, 0 equiv $\mathrm{PCy}_{3}$; blue squares, 1.0 equiv $\mathrm{PCy}_{3}$; gold triangles, 2.0 equiv $\mathrm{PCy}_{3}$; red diamonds, 3.0 equiv $\mathrm{PCy}_{3}$; and purple circles, 4.0 equiv. $\mathrm{PCy}_{3}$.]

metalation $/ \mathrm{SO}_{2}$ extrusion sequence being cleavage of the $\mathrm{Pd}-\mathrm{N}$ bond of the palladacycle 12, which should be independent of ligand concentration.

This set of stoichiometric experiments is in good agreement with the partial orders in catalyst obtained using substoichiometric amounts of $\mathrm{Pd}(\mathrm{OAc})_{2}$ in section 2.4.

2.6. Role of $\mathrm{K}_{2} \mathrm{CO}_{3}$. Unlike for the coupling of aryl halides with nucleophiles such as amines, alcohols, or thiols, there are no acidic protons to be removed in the coupling of sulfinate salts. Yet, a carbonate base, and, more specifically, potassium or cesium carbonate, is a crucial additive for the reaction. In the following section, we investigated the role of the carbonate base and of its countercation.

2.6.1. Role of the Carbonate. One molecule of sulfur dioxide is extruded every time a molecule of the biaryl product is generated. Therefore, since $5 \mathrm{~mol} \%$ of $\mathrm{Pd}(\mathrm{OAc})_{2}$ is used, a 20:1 ratio between the gaseous byproduct and the catalyst is reached at the end of the reaction. Since $\mathrm{SO}_{2}$ gas and $\mathrm{SO}_{2}$ surrogates have been utilized in many palladium-catalyzed $\mathrm{C}-$ $\mathrm{S}$ bond-forming reactions, ${ }^{20 \mathrm{~b}, 46}$ the $\mathrm{SO}_{2}$ generated in the present reactions is likely to coordinate to the palladium center, potentially disrupting catalysis.

Carbonate bases are reported to be efficient traps for $\mathrm{SO}_{2}$ gas in the waste stream from combustion in several industrial processes. ${ }^{47}$ Given this, we hypothesized that a carbonate base was necessary to trap the liberated $\mathrm{SO}_{2}$ in the reaction under 
a)
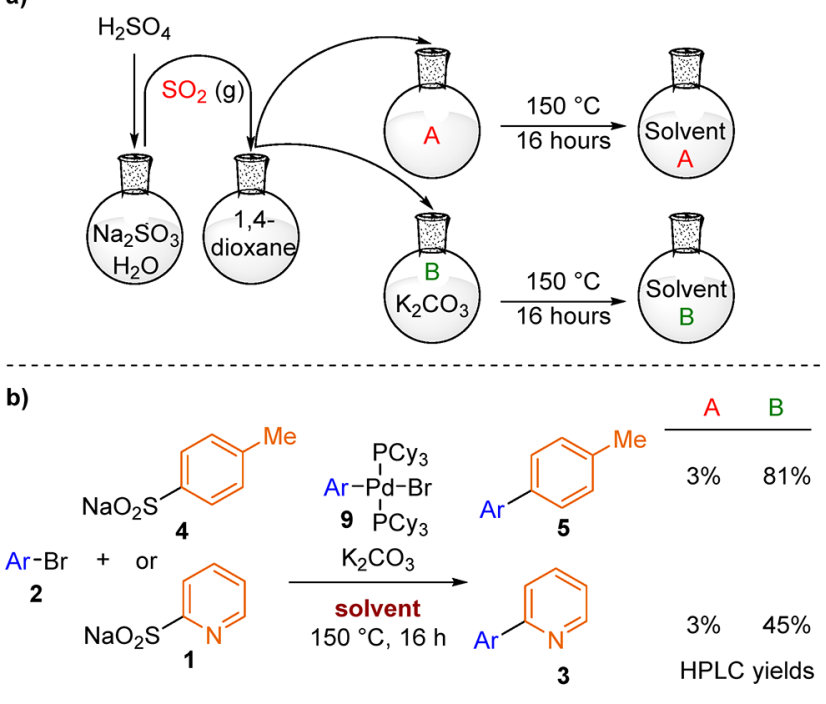

c)

$$
\mathrm{K}_{2} \mathrm{CO}_{3}+\mathrm{SO}_{2} \longrightarrow \mathrm{K}_{2} \mathrm{SO}_{3}+\mathrm{CO}_{2}
$$

Figure 10. Influence of $\mathrm{SO}_{2}$ and $\mathrm{K}_{2} \mathrm{CO}_{3}$ on the reaction: (a) generation of gaseous $\mathrm{SO}_{2}$, solvents $\mathrm{A}$ and $\mathrm{B}$; (b) reaction outcome; and (c) rationalization of the role of $\mathrm{K}_{2} \mathrm{CO}_{3}$.

study, preserving the catalyst and allowing reasonable turnover to be achieved. In order to test this, $0.05 \mathrm{M}$ solutions of $\mathrm{SO}_{2}$ gas in 1,4-dioxane were prepared and divided into an empty flask (A) or a flask containing $\mathrm{K}_{2} \mathrm{CO}_{3}$ (B). These flasks were then heated at $150{ }^{\circ} \mathrm{C}$ for $16 \mathrm{~h}$, which are the standard reaction time and temperature employed in productive catalytic crosscoupling reactions (Figure 10a). The obtained solvents $\mathrm{A}$ and $B$ were then used for reactions between aryl bromide 2 and carbocyclic and pyridine sulfinates 1 and 4, catalyzed by the oxidative addition product 9 . For both substrates, $3 \%$ product

Scheme 6. Toward a Lower Temperature Cross-Coupling ${ }^{d}$

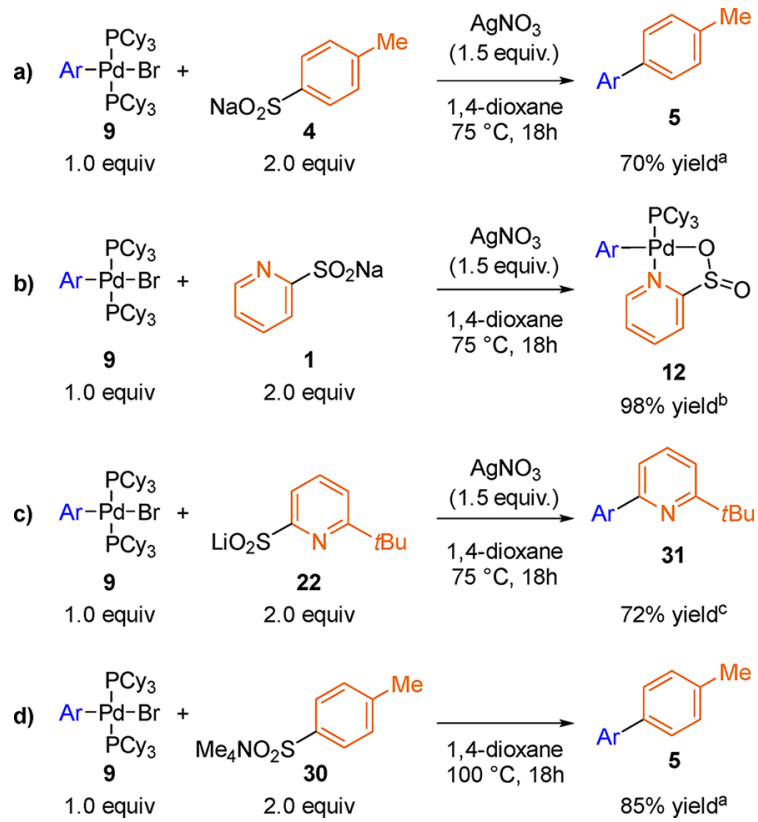

${ }^{a}$ HPLC yield against 1,3,5-trimethoxybenzene. ${ }^{b 19} \mathrm{~F}$ NMR yield based on starting material consumption. ${ }^{c 19} \mathrm{~F}$ NMR yield against 1fluoronaphtalene. ${ }^{d} \mathrm{Ar}=4-\mathrm{F}-\mathrm{C}_{6} \mathrm{H}_{4}$.
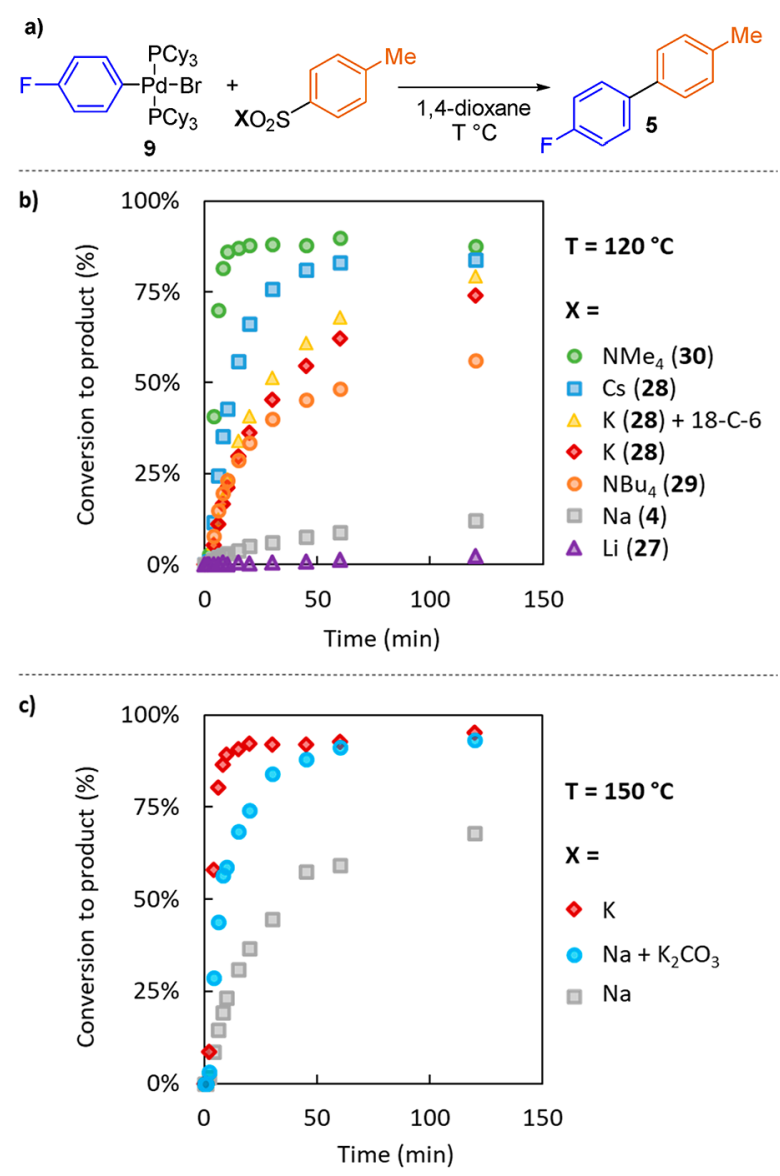

Figure 11. Influence of the cation on the rate of the transmetalation step.

(less than one turnover) was obtained when using solvent $\mathrm{A}$. Conversely, solvent $\mathrm{B}$, which contained $\mathrm{K}_{2} \mathrm{CO}_{3}$, provided $81 \%$ and $45 \%$ yields of products $\mathbf{5}$ and 3 , respectively (Figure 10b). These experiments show the importance of the carbonate base to sequester $\mathrm{SO}_{2}$. Based on literature reports, ${ }^{47,48}$ we conclude that sulfite anions are generated together with carbon dioxide, as shown in Figure 10c.

2.6.2. Role of the Cation. We demonstrated in sections 2.4. and 2.5 that the reaction involving pyridine-2-sulfinate sodium salt 1 is limited by the rate of $\mathrm{SO}_{2}$ extrusion, which does not involve the original sulfinate cation. Therefore, the role of the cation was studied for the reaction involving the carbocyclic sulfinate 4 , in which the cation is likely to be involved between the resting-state intermediate and the turnover-limiting step. We also showed in section 2.5 that the rate of extrusion of $\mathrm{SO}_{2}$ is extremely fast, compared to the rate of transmetalation for the carbocyclic substrate 4 . Therefore, in the following section, we have considered that the rate of product formation in the reaction between the oxidative addition complex and a sulfinate salt is representative of the rate of the transmetalation step. The reactions were performed at $120{ }^{\circ} \mathrm{C}$ using 2 equiv of sulfinate to 1 equiv of oxidative addition product 9 (Figure 11a).

Lithium sulfinate 27 showed almost no reactivity (2\% product formation in $2 \mathrm{~h}$ ). Similarly, sodium sulfinate 4 provided $12 \%$ product within $2 \mathrm{~h}$, whereas potassium sulfinate 25 reached $74 \%$ conversion to product (Figure 11b). Moving further down in the alkaline metals group, cesium sulfinate $\mathbf{2 8}$ 


\section{Scheme 7. Overall Mechanism}

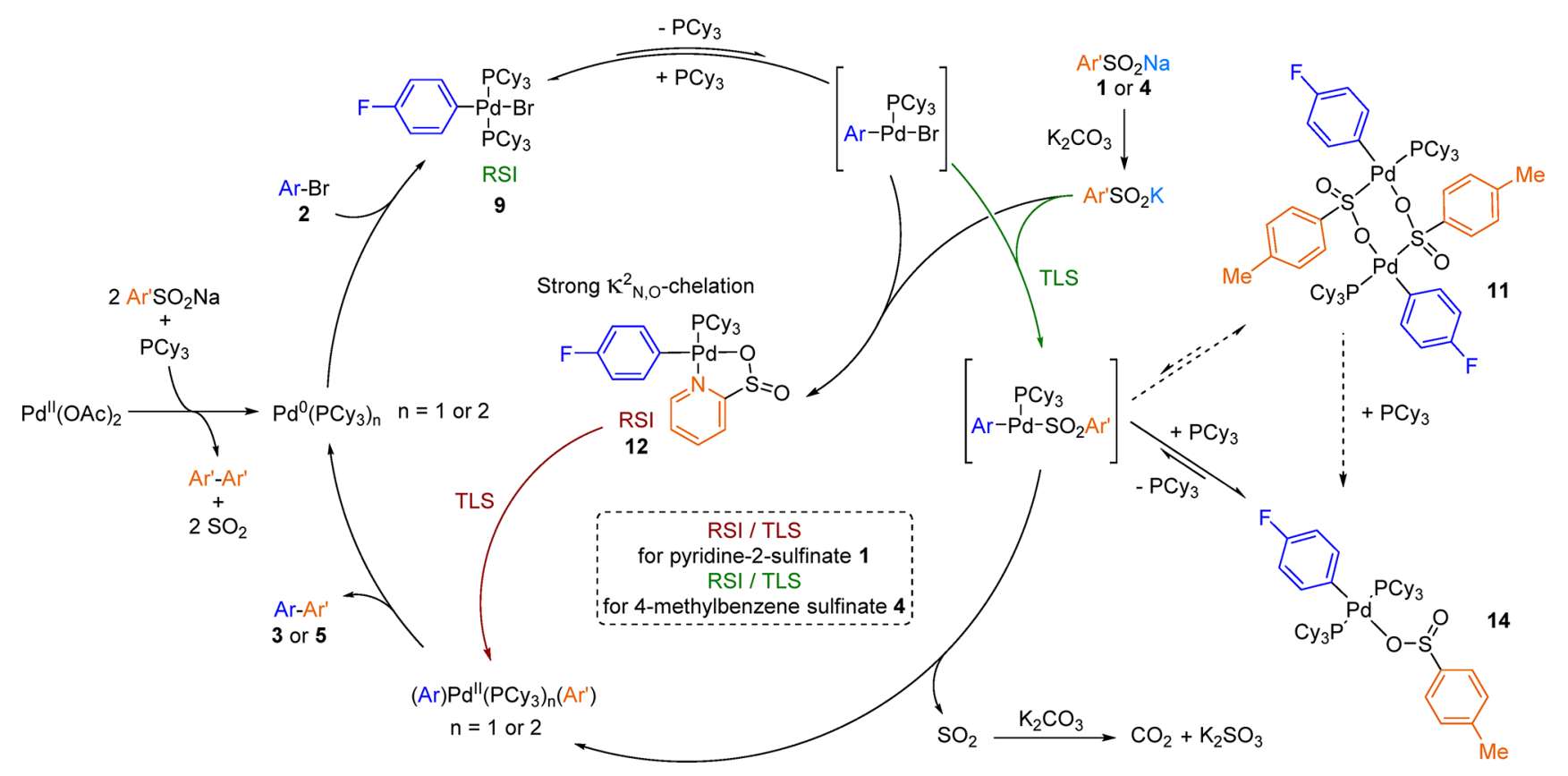

increased the rate significantly, with $84 \%$ product formation in the same time. Tetrabutylammonium sulfinate $\mathbf{2 9}$ had a similar initial rate, compared to the potassium sulfinate 20. However, the conversion did not rise above $60 \%$, even after $5 \mathrm{~h}$. This could be caused by Hofman-type elimination of the ammonium salt, leading to substrate decomposition. The use of 18-crown-6 only slightly increased the rate of anion exchange with $79 \%$ yield after 2 h. However, a dramatic increase in rate was observed with tetramethylammonium sulfinate 30, which led to $86 \%$ yield within the first $10 \mathrm{~min}$. The low performance of the tetrabutylammonium sulfinate salt, compared to the potassium, or cesium sulfinates suggests that solubility of the sulfinate salt is not correlated to the rate of the transmetalation step. Indeed, the tetrabutylammonium sulfinate is entirely soluble in 1,4-dioxane at $120^{\circ} \mathrm{C}$, while the alkali sulfinates are not. Tetramethylammonium salts have been used as silver surrogates to abstract halide atoms, ${ }^{49}$ which might explain the excellent reactivity of sulfinate $\mathbf{3 0}$ in the transmetalation step. When sodium sulfinate $\mathbf{4}$ was employed in a $1: 1$ ratio with $\mathrm{K}_{2} \mathrm{CO}_{3}$ at $150{ }^{\circ} \mathrm{C}$, the transmetalation occurred almost as quickly as the transmetalation involving potassium sulfinate $\mathbf{2 5}$ (Figure 11c). This suggests that the role of $\mathrm{K}_{2} \mathrm{CO}_{3}$, in addition to trapping liberated $\mathrm{SO}_{2}$, is to take part in a cation metathesis with the sodium sulfinate salt, thus facilitating transmetalation.

2.7. Toward Lower Temperatures. In section 2.2.3.1, the use of the silver salt $\mathrm{AgNO}_{3}$ allowed the synthesis of a variety of palladium sulfinate complexes at room temperature, starting from the oxidative addition complex 9. In other words, this additive allowed the transmetalation step to occur $125{ }^{\circ} \mathrm{C}$ below the temperatures needed in the catalytic system, presumably because of the high affinity between $\mathrm{Ag}$ and $\mathrm{Br}$ atoms. ${ }^{50}$ To confirm the viability of this additive based strategy for lowering the reaction temperature, stoichiometric reactions were performed between the oxidative addition complex 9 and carbocyclic and pyridyl sodium sulfinates $\mathbf{4}$ and $\mathbf{1}$ in the presence of $\mathrm{AgNO}_{3}$. Cross-coupling product 5 was obtained in $70 \%$ yield for the carbocyclic sulfinate, showing the potential of silver additives to promote reactivity for these types of substrates (Scheme 6a). However, for the heterocyclic sulfinate $\mathbf{1}$, only the corresponding palladium sulfinate complex 12 was obtained (Scheme 6b).

This suggests that an additive-based strategy that accelerates transmetalation will not be sufficient to achieve a lower temperature cross-coupling for substrates able to strongly chelate the palladium in a $\kappa_{\mathrm{N}, \mathrm{O}}^{2}$-fashion. For these systems, in addition to the transmetalation, there will be an additional challenge in disrupting the stabilizing chelation to the $\mathrm{Pd}$ center. This is consistent with the earlier results and was confirmed by the reaction shown in Scheme $6 c$, in which the sterically hindered 6-tert-butylpyridine-2-sulfinate salt $\mathbf{2 2}$ underwent a lower temperature cross coupling and delivered biaryl 31 in $72 \%$ yield. However, the use of silver salts was noncompatible with the catalytic reaction, presumably due to their ability to also act as oxidants. ${ }^{51}$ The tetramethylammonium alternative proved to be promising, providing the crosscoupling product 5 in $85 \%$ yield in the stoichiometric reaction between the oxidative addition complex 9 and the tetramethylammonium sulfinate 30 at $100{ }^{\circ} \mathrm{C}$ (Scheme $6 \mathrm{~d}$ ). We are currently investigating the use of such additives in the catalytic reaction, as well as alternative strategies to achieve lower temperature cross-couplings with carbocyclic and heterocyclic substrates.

\section{CONCLUSION}

The mechanism of the palladium-catalyzed desulfinative crosscoupling of aryl halides and sulfinate salts was investigated. The in situ reduction of the $\mathrm{Pd}(\mathrm{II})$ source to form the active $\operatorname{Pd}(0)$ species was shown to be mediated by the homocoupling of two sulfinate substrates. Novel palladium sulfinate complexes were independently synthesized, characterized, and proven to be competent intermediates in the catalytic reaction. The resting-state catalyst and the rate-determining step were identified. Their identity was heavily dependent on the nature of the sulfinate coupling partner, more specifically on the ability of the sulfinate to strongly chelate the palladium 
in a $\kappa_{\mathrm{N}, \mathrm{O}}^{2}$-mode. The kinetic data also suggest that both transmetalation and extrusion of $\mathrm{SO}_{2}$ most likely occurs after dissociation of a phosphine ligand in order to free a coordination site on palladium. Finally, we showed that the base has a dual role: the carbonate traps the generated sulfur dioxide and permits catalyst turnover, while the potassium countercation undergoes a cation metathesis with the sulfinate salt to allow a faster transmetalation step (Scheme 7).

In summary, isolation of novel palladium sulfinate complexes and kinetic analysis has allowed us to identify the key challenges to reduce the temperature of these reactions. Efforts toward reactions that proceed using milder conditions are currently underway.

\section{ASSOCIATED CONTENT}

\section{SI Supporting Information}

The Supporting Information is available free of charge at https://pubs.acs.org/doi/10.1021/jacs.9b13260.

\section{Crystallographic data (CIF)}

Experimental procedures and supporting characterization data and spectra (PDF)

\section{AUTHOR INFORMATION}

\section{Corresponding Author}

Michael C. Willis - Department of Chemistry, Chemistry Research Laboratories, University of Oxford, Oxford OX1 4TA, United Kingdom; (1) orcid.org/0000-0002-0636-6471; Email: michael.willis@chem.ox.ac.uk

\section{Authors}

Antoine de Gombert - Department of Chemistry, Chemistry Research Laboratories, University of Oxford, Oxford OX1 4TA, United Kingdom

Alasdair I. McKay - Department of Chemistry, Chemistry Research Laboratories, University of Oxford, Oxford OX1 4TA, United Kingdom; School of Chemistry, University of Melbourne, Parkville, VIC 3010, Australia

Christopher J. Davis - Vertex Pharmaceuticals (Europe), Ltd., Abingdon, Oxfordshire OX14 4RW, United Kingdom

Katherine M. Wheelhouse - Chemical Development, GSK Medicines Research Centre, Stevenage, Hertfordshire SG1 2NY, United Kingdom

Complete contact information is available at:

https://pubs.acs.org/10.1021/jacs.9b13260

\section{Notes}

The authors declare no competing financial interest.

\section{ACKNOWLEDGMENTS}

Richard Cooper (University of Oxford) is thanked for assistance with X-ray structure analysis, and Nader Amin and Tim Claridge (both University of Oxford) are thanked for assistance with NMR spectroscopy analysis. A.d.G. is grateful to the EPSRC Centre for Doctoral Training in Synthesis for Biology and Medicine (EP/L015838/1) for a studentship, and the generous support by GlaxoSmithKline, Vertex, AstraZeneca, Diamond Light Source, Defence Science and Technology Laboratory, Evotec, Janssen, Novartis, Pfizer, Syngenta, Takeda, and UCB is gratefully acknowledged.

\section{REFERENCES}

(1) Miyaura, N.; Yamada, K.; Suzuki, A. A New Stereospecific CrossCoupling by the Palladium-Catalyzed Reaction of 1-Alkenylboranes with 1-Alkenyl or 1-Alkynyl Halides. Tetrahedron Lett. 1979, 20, 3437-3440.

(2) (a) Carey, J. S.; Laffan, D.; Thomson, C.; Williams, M. T. Analysis of the Reactions Used for the Preparation of Drug Candidate Molecules. Org. Biomol. Chem. 2006, 4, 2337-2347. (b) Brown, D. G.; Boström, J. Analysis of Past and Present Synthetic Methodologies on Medicinal Chemistry: Where Have All the New Reactions Gone? J. Med. Chem. 2016, 59, 4443-4458.

(3) Cox, P. A.; Leach, A. G.; Campbell, A. D.; Lloyd-Jones, G. C. Protodeboronation of Heteroaromatic, Vinyl, and Cyclopropyl Boronic Acids: pH-Rate Profiles, Autocatalysis, and Disproportionation. J. Am. Chem. Soc. 2016, 138, 9145-9157.

(4) Markovic, T.; Rocke, B. N.; Blakemore, D. C.; Mascitti, V.; Willis, M. C. Pyridine Sulfinates as General Nucleophilic Coupling Partners in Palladium-Catalyzed Cross-Coupling Reactions with Aryl Halides. Chem. Sci. 2017, 8, 4437-4442.

(5) Markovic, T.; Rocke, B. N.; Blakemore, D. C.; Mascitti, V.; Willis, M. C. Catalyst Selection Facilitates the Use of Heterocyclic Sulfinates as General Nucleophilic Coupling Partners in PalladiumCatalyzed Coupling Reactions. Org. Lett. 2017, 19, 6033-6035.

(6) Markovic, T.; Murray, P. R. D.; Rocke, B. N.; Shavnya, A.; Blakemore, D. C.; Willis, M. C. Heterocyclic Allylsulfones as Latent Heteroaryl Nucleophiles in Palladium-Catalyzed Cross-Coupling Reactions. J. Am. Chem. Soc. 2018, 140, 15916-15923.

(7) Ortgies, D. H.; Hassanpour, A.; Chen, F.; Woo, S.; Forgione, P. Desulfination as an Emerging Strategy in Palladium-Catalyzed C-C Coupling Reactions. Eur. J. Org. Chem. 2016, 2016, 408-425.

(8) Garves, K. Coupling, Carbonylation, and Vinylation Reactions of Aromatic Sulfinic Acids via Organopalladium Intermediates. J. Org. Chem. 1970, 35, 3273-3275.

(9) (a) Zhou, X.; Luo, J.; Liu, J.; Peng, S.; Deng, G.-J. Pd-Catalyzed Desulfitative Heck Coupling with Dioxygen as the Terminal Oxidant. Org. Lett. 2011, 13, 1432-1435. (b) Wang, G. W.; Miao, T. Palladium-Catalyzed Desulfitative Heck-Type Reaction of Aryl Sulfinic Acids with Alkenes. Chem. - Eur. J. 2011, 17, 5787-5790.

(10) Cheng, K.; Yu, H.-Z.; Zhao, B.; Hu, S.; Zhang, X.-M.; Qi, C. Palladium-Catalyzed Desulfitative Cross-Coupling of Arylsulfinates with Arylboronic Acids. RSC Adv. 2014, 4, 57923-57928.

(11) Cheng, K.; Hu, S.; Zhao, B.; Zhang, X. M.; Qi, C. PalladiumCatalyzed Hiyama-Type Cross-Coupling Reactions of Arenesulfinates with Organosilanes. J. Org. Chem. 2013, 78, 5022-5025.

(12) Sato, K.; Okoshi, T. Process for Producing Aromatic Compounds. U.S. Patent No. US5159082A, 1992.

(13) (a) Forgione, P.; Ortgies, D. A Ligand-Free PalladiumCatalyzed Cross-Coupling of Aryl Sulfinates with Aryl Bromides. Synlett 2013, 24, 1715-1721. (b) Zhou, C.; Liu, Q.; Li, Y.; Zhang, R.; $\mathrm{Fu}, \mathrm{X}$.; Duan, C. Palladium-Catalyzed Desulfitative Arylation by C-O Bond Cleavage of Aryl Triflates with Sodium Arylsulfinates. J. Org. Chem. 2012, 77, 10468-10472. (c) Zhou, C.; Li, Y.; Lu, Y.; Zhang, R.; Jin, K.; Fu, X.; Duan, C. Palladium-Catalyzed Desulfitative CrossCoupling of Sodium Arylsulfinates with Aryl Bromides and Chlorides: An Alternative Convenient Synthesis of Biaryls. Chin. J. Chem. 2013, 31, 1269-1273. (d) Zhao, F.; Tan, Q.; Xiao, F.; Zhang, S.; Deng, G.-J. Palladium-Catalyzed Desulfitative Cross-Coupling Reaction of Sodium Sulfinates with Benzyl Chlorides. Org. Lett. 2013, 15, 1520-1523. (e) Forgione, P.; Ortgies, D.; Barthelme, A.; Aly, S.; Desharnais, B.; Rioux, S. Scope of the Desulfinylative PalladiumCatalyzed Cross-Coupling of Aryl Sulfinates with Aryl Bromides. Synthesis 2013, 45, 694-702.

(14) (a) Chen, W.; Li, P.; Miao, T.; Meng, L. G.; Wang, L. An Efficient Tandem Elimination-Cyclization-Desulfitative Arylation of 2-(Gem-Dibromovinyl)Phenols(Thiophenols) with Sodium Arylsulfinates. Org. Biomol. Chem. 2013, 11, 420-424. (b) Sévigny, S.; Forgione, P. Efficient Desulfinylative Cross-Coupling of Thiophene and Furan Sulfinates with Aryl Bromides in Aqueous Media. New J. Chem. 2013, 37, 589. (c) Colomb, J.; Billard, T. Palladium-Catalyzed 
Desulfitative Arylation of 3-Haloquinolines with Arylsulfinates. Tetrahedron Lett. 2013, 54, 1471-1474. (d) Shi, J.; Tang, X.-D.; Wu, Y.-C.; Li, H.-N.; Song, L.-J.; Wang, Z.-Y. Palladium-Catalyzed Desulfitative Arylation of 5-Alkoxy-3,4-dibromo-2 $(5 H)$-furanone with Sodium Arylsulfinates. Eur. J. Org. Chem. 2015, 2015, 1193-1197. (e) Mangel, D.; Buonomano, C.; Sévigny, S.; Di Censo, G.; Thevendran, G.; Forgione, P. Efficient Desulfinative Cross-Coupling of Heteroaromatic Sulfinates with Aryl Triflate in Environmentally Friendly Protic Solvents. Heterocycles 2015, 90, 1228-1239.

(15) (a) Ortgies, D. H.; Chen, F.; Forgione, P. Palladium and TEMPO as Co-Catalysts in a Desulfinative Homocoupling Reaction. Eur. J. Org. Chem. 2014, 2014, 3917-3922. (b) Rao, B.; Zhang, W.; $\mathrm{Hu}$, L.; Luo, M. Catalytic Desulfitative Homocoupling of Sodium Arylsulfinates in Water using $\mathrm{PdCl}_{2}$ as the Recyclable Catalyst and $\mathrm{O}_{2}$ as the Terminal Oxidant. Green Chem. 2012, 14, 3436-3440.

(16) Tanaka, D.; Romeril, S. P.; Myers, A. G. On the Mechanism of the Palladium(II)-Catalyzed Decarboxylative Olefination of Arene Carboxylic Acids. Crystallographic Characterization of Non-Phosphine Palladium(II) Intermediates and Observation of Their Stepwise Transformation in Heck-like Processes. J. Am. Chem. Soc. 2005, 127, $10323-10333$.

(17) Zhang, S.-L.; Fu, Y.; Shang, R.; Guo, Q.-X.; Liu, L. Theoretical Analysis of Factors Controlling Pd-Catalyzed Decarboxylative Coupling of Carboxylic Acids with Olefins. J. Am. Chem. Soc. 2010, $132,638-646$.

(18) Adenot, A.; Char, J.; Von Wolff, N.; Lefevre, G.; AnthoreDalion, L.; Cantat, T. $\mathrm{SO}_{2}$ Conversion to Sulfones: Development and Mechanistic Insights of a Sulfonylative Hiyama Cross-Coupling. Chem. Commun. 2019, 55, 12924-12927.

(19) (a) Sraj, L. O. C.; Khairallah, G. N.; da Silva, G.; O’Hair, R. A. J. Who Wins: Pesci, Peters, or Deacon? Intrinsic Reactivity Orders for Organocuprate Formation via Ligand Decomposition. Organometallics 2012, 31, 1801-1807. (b) Skillinghaug, B.; Skold, C.; Rydfjord, J.; Svensson, F.; Behrends, M.; Savmarker, J.; Sjoberg, P. J.; Larhed, M. Palladium(II)-Catalyzed Desulfitative Synthesis of Aryl Ketones from Sodium Arylsulfinates and Nitriles: Scope, Limitations, and Mechanistic Studies. J. Org. Chem. 2014, 79, 12018-12032. (c) Behrends, M.; Sävmarker, J.; Sjöberg, P. J. R.; Larhed, M. Microwave-Assisted Palladium(II)-Catalyzed Synthesis of Aryl Ketones from Aryl Sulfinates and Direct ESI-MS Studies Thereof. ACS Catal. 2011, 1, 1455-1459.

(20) (a) Baskin, J. M.; Wang, Z. A Mild, Convenient Synthesis of Sulfinic Acid Salts and Sulfonamides from Alkyl and Aryl Halides. Tetrahedron Lett. 2002, 43, 8479-8483. (b) Emmett, E. J.; Hayter, B. R.; Willis, M. C. Palladium-Catalyzed Synthesis of Ammonium Sulfinates from Aryl Halides and a Sulfur Dioxide Surrogate: a Gasand Reductant-Free Process. Angew. Chem., Int. Ed. 2014, 53, 1020410208. (c) Kamiyama, T.; Enomoto, S.; Inoue, M. A Novel Synthesis of Aromatic Sulfinic Acids. Chem. Pharm. Bull. 1988, 36, 2652-2653. (d) Skillinghaug, B.; Rydfjord, J.; Odell, L. R. Synthesis of sodium aryl sulfinates from aryl bromides employing 1,4-diazabicyclo[2.2.2] octane bis(sulfur dioxide) adduct (DABSO) as a bench-stable, gas-free alternative to $\mathrm{SO}_{2}$. Tetrahedron Lett. 2016, 57, 533-536.

(21) (a) Wei, C. S.; Davies, G. H.; Soltani, O.; Albrecht, J.; Gao, Q.; Pathirana, C.; Hsiao, Y.; Tummala, S.; Eastgate, M. D. The Impact of Palladium(II) Reduction Pathways on the Structure and Activity of Palladium(0) Catalysts. Angew. Chem., Int. Ed. 2013, 52, 5822-5826. (b) Amatore, C.; Jutand, A.; M'Barki, M. A. Evidence of the Formation of Zerovalent Palladium from $\mathrm{Pd}(\mathrm{OAc})_{2}$ and Triphenylphosphine. Organometallics 1992, 11, 3009-3013. (c) Norton, D. M.; Mitchell, E. A.; Botros, N. R.; Jessop, P. G.; Baird, M. C. A superior precursor for palladium(0)-based cross-coupling and other catalytic reactions. J. Org. Chem. 2009, 74, 6674-80. (d) Li, H.; Grasa, G. A.; Colacot, J. A Highly Efficient, Practical, and General Route for the Synthesis of $\left(\mathrm{R}_{3} \mathrm{P}\right)_{2} \mathrm{Pd}(0)$ Structural Evidence on the Reduction Mechanism of $\mathrm{Pd}(\mathrm{II})$ to $\mathrm{Pd}(0)$. Org. Lett. 2010, 12, 3332-3335.

(22) Amatore, C.; Jutand, A. Anionic $\operatorname{Pd}(0)$ and $\mathrm{Pd}(\mathrm{II})$ Intermediates in Palladium-Catalyzed Heck and Cross-Coupling Reactions. Acc. Chem. Res. 2000, 33, 314-321.
(23) Negishi, E.; Takahashi, T.; Akiyoshi, K. 'Bis(triphenylphosphine)palladium:' Its Generation, Characterization, and Reactions. J. Chem. Soc., Chem. Commun. 1986, 1338-1339.

(24) Milstein, D.; Stille, J. K. Palladium-Catalyzed Coupling of Tetraorganotin Compounds with Aryl and Benzyl Halides. Synthetic Utility and Mechanism. J. Am. Chem. Soc. 1979, 101, 4992-4998.

(25) Steinhoff, B. A.; Stahl, S. S. Ligand-Modulated Palladium Oxidation Catalysis Mechanistic Insights into Aerobic Alcohol Oxidation with the $\mathrm{Pd}(\mathrm{OAc})_{2}$ Pyridine Catalyst System. Org. Lett. 2002, 4, 4179-4181.

(26) (a) Louie, J.; Hartwig, J. F. A Route to $\mathrm{Pd}^{0}$ from $\mathrm{Pd}^{\mathrm{II}}$ Metallacycles in Animation and Cross-Coupling Chemistry. Angew. Chem., Int. Ed. Engl. 1996, 35, 2359-2361. (b) Strieter, E. R.; Blackmond, D. G.; Buchwald, S. L. Insights into the Origin of High Activity and Stability of Catalysts Derived from Bulky, Electron-Rich Monophosphinobiaryl Ligands in the Pd-Catalyzed C-N Bond Formation. J. Am. Chem. Soc. 2003, 125, 13978-13980.

(27) Huang, X.; Anderson, K. W.; Zim, D.; Jiang, L.; Klapars, A.; Buchwald, S. L. Expanding Pd-Catalyzed C-N Bond-Forming Processes: The First Amidation of Aryl Sulfonates, Aqueous Amination, and Complementarity with $\mathrm{Cu}$-Catalyzed Reactions. J. Am. Chem. Soc. 2003, 125, 6653-6655.

(28) Thirupathi, N.; Amoroso, D.; Bell, A.; Protasiewicz, J. D. Reactivity Studies of Cationic Palladium(II) Phosphine Carboxylate Complexes with Lewis Bases; Substitution versus Cyclometalation. Organometallics 2007, 26, 3157-3166.

(29) Li, K.; Guzei, I. A.; Darkwa, J. Insertion of Sulfur Dioxide into Metal Carbon Bonds of Chloro(methyl)palladium Complexes. Polyhedron 2003, 22, 805-810.

(30) Shrestha, R.; Brennessel, W. W.; Weix, D. J. [2,2'-Bis(diphenylphosphanyl)-1,1'-binaphthyl-[kappa]2P, $\left.\mathrm{P}^{\prime}\right]$ chlorido (4methylphenylsulfonyl-[kappa]S)palladium(II) dichloromethane trisolvate monohydrate. Acta Crystallogr., Sect. E: Struct. Rep. Online 2011, 67, m1830.

(31) Higashi, L. S.; Lundeen, M.; Hilti, E.; Seff, K. Crystal and Molecular Structure of $\mathrm{Bis}(2$-pyridine sulfinato)copper(II). Inorg. Chem. 1977, 16, 310-313.

(32) Mitchell, E. A.; Jessop, P. G.; Baird, M. C. A Kinetics Study of the Oxidative Addition of Bromobenzene to $\mathrm{Pd}\left(\mathrm{PCy}_{3}\right)_{2}$ ( $\mathrm{Cy}=$ cyclohexyl) in a Nonpolar Medium: The Influence on Rates of Added $\mathrm{PCy}_{3}$ and Bromide Ion. Organometallics 2009, 28, 6732-6738.

(33) Barrios-Landeros, F.; Carrow, B. P.; Hartwig, J. F. Effect of Ligand Steric Properties and Halide Identity on the Mechanism for Oxidative Addition of Haloarenes to Trialkylphosphine $\operatorname{Pd}(0)$ Complexes. J. Am. Chem. Soc. 2009, 131, 8141-8154.

(34) (a) Grushin, V. V.; Bensimon, C.; Alper, H. Dichlorobis(tricyclohexylphosphine)palladium(II) Synthesis and Crystal Structure. An Exceptionally Simple and Efficient Preparation of Bis(tricyclohexylphosphine)palladium(0). Inorg. Chem. 1994, 33, 48044806. (b) Stambuli, J. P.; Incarvito, C. D.; Bühl, M.; Hartwig, J. F. Synthesis, Structure, Theoretical Studies, and Ligand Exchange Reactions of Monomeric, T-Shaped Arylpalladium(II) Halide Complexes with an Additional, Weak Agostic Interaction. J. Am. Chem. Soc. 2004, 126, 1184-1194.

(35) (a) Lindsell, W. E.; Palmer, D. D.; Preston, P. N.; Rosair, G. M.; Jones, R. V. H.; Whitton, A. J. Investigations of Benzyl and Aryl Palladium Complexes with Pendant Hydroxy Substituents and Their Transformation into Benzolactones on Carbonylation. Organometallics 2005, 24, 1119-1133. (b) Hartwig, J. F. Transition Metal Catalyzed Synthesis of Arylamines and Aryl Ethers from Aryl Halides and Triflates: Scope and Mechanism. Angew. Chem., Int. Ed. 1998, 37, 2046-2067. (c) Widenhoefer, R. A.; Buchwald, S. L. Electronic Dependence of $\mathrm{C}-\mathrm{O}$ Reductive Elimination from Palladium (Aryl)neopentoxide Complexes. J. Am. Chem. Soc. 1998, 120, 6504-6511. (d) Widenhoefer, R. A.; Zhong, H. A.; Buchwald, S. L. Direct Observation of $\mathrm{C}-\mathrm{O}$ Reductive Elimination from Palladium Aryl Alkoxide Complexes To Form Aryl Ethers. J. Am. Chem. Soc. 1997, $119,6787-6795$. 
(36) (a) Klinkenberg, J. L.; Hartwig, J. F. Slow Reductive Elimination from Arylpalladium Parent Amido Complexes. J. Am. Chem. Soc. 2010, 132, 11830-11833. (b) Arrechea, P. L.; Buchwald, S. L. Biaryl Phosphine Based Pd(II) Amido Complexes: The Effect of Ligand Structure on Reductive Elimination. J. Am. Chem. Soc. 2016, 138, 12486-12493.

(37) Alvaro, E.; Hartwig, J. F. Resting State and Elementary Steps of the Coupling of Aryl Halides with Thiols Catalyzed by Alkylbisphosphine Complexes of Palladium. J. Am. Chem. Soc. 2009, 131, $7858-7868$

(38) (a) Grushin, V. V.; Alper, H. Indirect Formation of Carboxylic Acids via Anhydrides in the Palladium-Catalyzed Hydroxycarbonylation of Aromatic Halides. J. Am. Chem. Soc. 1995, 117, 4305-4315. (b) Meyer, W. H.; Brüll, R.; Raubenheimer, H. G.; Thompson, C.; Kruger, G. J. Thioethercarboxylates in Palladium Chemistry: First Proof of Hemilabile Properties of S-O Ligands. J. Organomet. Chem. 1998, 553, 83-90.

(39) Shavnya, A.; Hesp, K. D.; Mascitti, V.; Smith, A. C. PalladiumCatalyzed Synthesis of (Hetero)Aryl Alkyl Sulfones from (Hetero)Aryl Boronic Acids, Unactivated Alkyl Halides, and Potassium Metabisulfite. Angew. Chem., Int. Ed. 2015, 54, 13571-13575.

(40) Vitzthum, G.; Lindner, E. Sulfinato Complexes. Angew. Chem., Int. Ed. Engl. 1971, 10, 315-326.

(41) Cámpora, J.; López, J. A.; Palma, P.; del Rio, D.; Carmona, E.; Valerga, P.; Graiff, C.; Tiripicchio, A. Synthesis and Insertion Reactions of the Cyclometalated Palladium-Alkyl Complexes Pd$\left(\mathrm{CH}_{2} \mathrm{CMe}_{2}-o-\mathrm{C}_{6} \mathrm{H}_{4}\right) \mathrm{L}_{2}$. Observation of a Pentacoordinated Intermediate in the Insertion of $\mathrm{SO}_{2}$. Inorg. Chem. 2001, 40, 4116-4126.

(42) (a) van Strijdonck, G. P. F.; Boele, M. D. K.; Kamer, P. C. J.; de Vries, J. G.; van Leeuwen, P. W. N. M. Fast Palladium Catalyzed Arylation of Alkenes Using Bulky Monodentate Phosphorus Ligands. Eur. J. Inorg. Chem. 1999, 1999, 1073-1076. (b) Sewell, L. J.; Huertos, M. A.; Dickinson, M. E.; Weller, A. S.; Lloyd-Jones, G. C. Dehydrocoupling of Dimethylamine Borane Catalyzed by Rh$\left(\mathrm{PCy}_{3}\right)_{2} \mathrm{H}_{2} \mathrm{Cl}$. Inorg. Chem. 2013, 52, 4509-4516. (c) Rosner, T.; Le Bars, J.; Pfaltz, A.; Blackmond, D. G. Kinetic Studies of Heck Coupling Reactions Using Palladacycle Catalysts: Experimental and Kinetic Modeling of the Role of Dimer Species. J. Am. Chem. Soc. 2001, 123, 1848-1855.

(43) (a) Marshall, J. E.; Keister, J. B.; Diver, S. T. Mechanism of Intermolecular Ene-yne Metathesis Promoted by the Grubbs FirstGeneration Catalyst: An Alternative Entry Point to Catalysis. Organometallics 2011, 30, 1319-1321. (b) Dias, E. L.; Nguyen, S. T.; Grubbs, R. H. Well-Defined Ruthenium Olefin Metathesis Catalysts: Mechanism and Activity. J. Am. Chem. Soc. 1997, 119, 3887-3897.

(44) Mitchell, E. A.; Baird, M. C. Optimization of Procedures for the Syntheses of Bisphosphinepalladium(0) Precursors for SuzukiMiyaura and Similar Cross-Coupling Catalysis: Identification of 3:1 Coordination Compounds in Catalyst Mixtures Containing $\operatorname{Pd}(0)$, $\mathrm{PCy}_{3}$, and/or $\mathrm{PMet} \mathrm{Bu}_{2}$. Organometallics 2007, 26, 5230-5238.

(45) (a) Brown, T. L.; Lee, K. J. Ligand Steric Properties. Coord. Chem. Rev. 1993, 128, 89-116. (b) Tolman, C. A. Steric Effects of Phosphorus Ligands in Organometallic Chemistry and Homogeneous Catalysis. Chem. Rev. 1977, 77, 313-348. (c) Wilson, M. R.; Woska, D. C.; Prock, A.; Giering, W. P. The Quantitative Analysis of Ligand Effects (QALE). The aryl effect. Organometallics 1993, 12, 17421752.

(46) (a) An, Y.; Xia, H.; Wu, J. A Palladium-Catalyzed Coupling Reaction of Aryl Nonaflates, Sulfur Dioxide, and Hydrazines. Org. Biomol. Chem. 2016, 14, 1665-1669. (b) Davies, A. T.; Curto, J. M.; Bagley, S. W.; Willis, M. C. One-Pot Palladium-Catalyzed Synthesis of Sulfonyl Fluorides from Aryl Bromides. Chem. Sci. 2017, 8, 12331237. (c) Nguyen, B.; Emmett, E. J.; Willis, M. C. PalladiumCatalyzed Aminosulfonylation of Aryl Halides. J. Am. Chem. Soc. 2010, 132, 16372-16373. (d) Richards-Taylor, C. S.; Blakemore, D. C.; Willis, M. C. One-Pot Three-Component Sulfone Synthesis Exploiting Palladium-Catalysed Aryl Halide Aminosulfonylation. Chem. Sci. 2014, 5, 222-228. (e) Shavnya, A.; Coffey, S. B.; Smith,
A. C.; Mascitti, V. Palladium-Catalyzed Sulfination of Aryl and Heteroaryl Halides: Direct Access to Sulfones and Sulfonamides. Org. Lett. 2013, 15, 6226-6229. (f) Ye, S.; Wu, J. A Palladium-Catalyzed Reaction of Aryl Halides, Potassium Metabisulfite, and Hydrazines. Chem. Commun. 2012, 48, 10037-10039.

(47) Kimura, S.; Smith, J. M. Kinetics of the Sodium CarbonateSulfur dioxide Reaction. AIChE J. 1987, 33, 1522-1532.

(48) (a) Anthony, E. J.; Granatstein, D. L. Sulfation Phenomena in Fluidized Bed Combustion Systems. Prog. Energy Combust. Sci. 2001, 27, 215-236. (b) Wappel, D.; Joswig, S.; Khan, A. A.; Smith, K. H.; Kentish, S. E.; Shallcross, D. C.; Stevens, G. W. The Solubility of Sulfur Dioxide and Carbon Dioxide in an Aqueous Solution of Potassium Carbonate. Int. J. Greenhouse Gas Control 2011, 5, 14541459.

(49) Arroniz, C.; Denis, J. G.; Ironmonger, A.; Rassias, G.; Larrosa, I. An Organic Cation as a Silver(I) analogue for the Arylation of $\mathrm{sp}^{2}$ and $\mathrm{sp}^{3} \mathrm{C}-\mathrm{H}$ Bonds with Iodoarenes. Chem. Sci. 2014, 5, 3509-3514.

(50) (a) Benson, S. W. III - Bond energies. J. Chem. Educ. 1965, 42, 502. (b) Kerr, J. A. Bond Dissociation Energies by Kinetic Methods. Chem. Rev. 1966, 66, 465-500.

(51) Beccalli, E. M.; Broggini, G.; Martinelli, M.; Sottocornola, S. $\mathrm{C}-\mathrm{C}, \mathrm{C}-\mathrm{O}, \mathrm{C}-\mathrm{N}$ Bond Formation on $\mathrm{sp}^{2}$ Carbon by $\mathrm{Pd}(\mathrm{II})-$ Catalyzed Reactions Involving Oxidant Agents. Chem. Rev. 2007, 107, $5318-5365$. 